\title{
A novel method for online analysis of gas and particle composition: description and evaluation of a Filter Inlet for Gases and AEROsols (FIGAERO)
}

\author{
F. D. Lopez-Hilfiker ${ }^{1}$, C. Mohr ${ }^{1}$, M. Ehn ${ }^{2,3}$, F. Rubach ${ }^{3}$, E. Kleist ${ }^{4}$, J. Wildt ${ }^{4}$, Th. F. Mentel ${ }^{3}$, A. Lutz ${ }^{5}$, M. Hallquist ${ }^{5}$, \\ D. Worsnop ${ }^{2,6}$, and J. A. Thornton ${ }^{1,2,3}$ \\ ${ }^{1}$ Department of Atmospheric Sciences, University of Washington, Seattle, WA 98195, USA \\ ${ }^{2}$ Department of Physics, P.O. Box 64, 00014, University of Helsinki, Helsinki, Finland \\ ${ }^{3}$ Institute for Energy and Climate Research (IEK-8), Forschungszentrum Jülich, 52425 Jülich, Germany \\ ${ }^{4}$ Institute of Bio- and Geosciences (IBG-2), Forschungszentrum Jülich, 52425 Jülich, Germany \\ ${ }^{5}$ Atmospheric Science, Department of Chemistry and Molecular Biology, University of Gothenburg, \\ 41296 Gothenburg, Sweden \\ ${ }^{6}$ Center for Aerosol and Cloud Chemistry, Aerodyne Research, Inc., Billerica, MA, USA \\ Correspondence to: J. A. Thornton (thornton@atmos.washington.edu)
}

Received: 1 October 2013 - Published in Atmos. Meas. Tech. Discuss.: 30 October 2013

Revised: 13 February 2014 - Accepted: 21 February 2014 - Published: 15 April 2014

\begin{abstract}
We describe a novel inlet that allows measurement of both gas and particle molecular composition when coupled to mass spectrometric, chromatographic, or optical sensors: the Filter Inlet for Gases and AEROsols (FIGAERO). The design goals for the FIGAERO are to allow unperturbed observation of ambient air while simultaneously analyzing gases and collecting particulate matter on a Teflon ${ }^{\circledR}$ (hereafter Teflon) filter via an entirely separate sampling port. The filter is analyzed periodically by the same sensor on hourly or faster timescales using temperature-programmed thermal desorption. We assess the performance of the FIGAERO by coupling it to a high-resolution time-of-flight chemical-ionization mass spectrometer (HRToF-CIMS) in laboratory chamber studies of $\alpha$-pinene oxidation and field measurements at a boreal forest location. Low instrument backgrounds give detection limits of ppt or lower for compounds in the gas-phase and in the picogram $\mathrm{m}^{-3}$ range for particle phase compounds. The FIGAERO-HRToF-CIMS provides molecular information about both gases and particle composition on the $1 \mathrm{~Hz}$ and hourly timescales, respectively for hundreds of compounds. The FIGAERO thermal desorptions are highly reproducible (better than $10 \%$ ), allowing a calibrated assessment of the effective volatility of desorbing compounds and the role of thermal decomposition during the
\end{abstract}

desorption process. We show that the often multi-modal desorption thermograms arising from secondary organic aerosol (SOA) provide additional insights into molecular composition and/or particle morphology, and exhibit changes with changes in SOA formation or aging pathways.

\section{Introduction}

Aerosol particles scatter and absorb radiation, influence cloud formation processes and properties, provide surfaces to facilitate multi-phase reactions, and affect trace gas concentrations by providing an adsorptive medium for semi-volatile gases. As a result, aerosol particles have a significant effect on the radiative balance of the atmosphere and thus on earth's climate (Hallquist et al., 2009). Atmospheric particles also have adverse effects on human health, impacting respiratory and cardiovascular systems (Davidson et al., 2005; Hallquist et al., 2009; Pope III and Dockery, 2006).

Of specific importance to both air quality and climate are particles smaller than $\sim 1 \mu \mathrm{m}$ in diameter, a significant and ubiquitous portion of which is secondary organic aerosol (SOA) (Hallquist et al., 2009; Jimenez et al., 2009). The sources, aging, and chemical properties of SOA still 
remain highly uncertain, and these uncertainties can lead to large errors between modeled and measured aerosol loadings (Volkamer et al., 2006). These errors limit our ability to confidently predict future changes in aerosol particle composition and concentration under a warming climate (Hallquist et al., 2009). To develop adequate model parameterizations of organic aerosol (OA) and its formation, growth, and loss, there remains a need to improve source apportionment capabilities and to develop and test chemical mechanisms that involve conversion and partitioning of organic compounds between gas and condensed phase. Both of these needs are facilitated by a more detailed understanding of molecular composition in both phases at higher time resolution. Measurements of specific tracers on timescales similar to the typical variability in emissions, photochemical activity, and meteorology, arguably an hour or shorter in polluted regions, would improve source apportionment, testing of partitioning theory (Pankow, 2007), and characterization of molecular properties such as the distribution of average oxidation state across carbon number (Kroll et al., 2011) against mechanistic photochemical models.

A range of methods are available to measure trace gases online and in situ; however, measurements of molecular composition of aerosol particles have so far mostly been conducted offline, using high-volume filter samplers, which typically integrate aerosol composition over 12-24 h (Turpin et al., 2000). More recently, online techniques have been developed, but while providing important constraints on elemental composition, the most common approaches are generally not suitable for molecular analysis of the organic aerosol fraction. The aerosol mass spectrometer (AMS), which measures non-refractory particle composition in the $0.050-1 \mu \mathrm{m}$ size range at high time resolution was a major breakthrough in quantifying organic aerosol time evolution and absolute mass concentrations (Canagaratna et al., 2007; DeCarlo et al., 2006; Jayne et al., 2000). Another example of a bulk particle composition measurement is the particle beam temperatureprogrammed desorption mass spectrometer which uses an aerodynamic lens for focusing aerosol to a desorption plate (Tobias et al., 2000). Single particle mass spectrometers (ex. SPLAT, PALMS, ATOFMS, Laser Desorption MS, and the RSMS III) provide a detailed picture of individual particles and thus particle mixing state (Gard et al., 1997; Lake et al., 2003; McKeown et al., 1991; Thomson et al., 2000; Zelenyuk and Imre, 2005). However, as with electron impact ionization employed in the AMS, laser desorption and ionization lead to highly fragmented organic ions, erasing the individual molecular identity of the OA components. Particle into liquid samplers (PILS) have been coupled to ion chromatography and mass spectrometer systems to measure aerosol composition (Saarnio et al., 2013; Weber et al., 2001) but are generally used to measure water soluble compounds only. Another separation technique using a pumped counter flow virtual impactor coupled to a vaporizer and atmosphericpressure chemical-ionization ion trap mass spectrometer was developed for the detection of organic acids (Vogel et al., 2013). Moreover, instruments for atmospheric applications have typically been designed for either exclusive gas or particulate phase analysis.

Recently, to study the dynamic organic aerosol system in a molecular framework, online methods to analyze both gas and particle phase molecular composition on timescales much faster than typical high-volume filter analyses have been developed. These include inline volatilization methods (Aljawhary et al., 2013; Hearn and Smith, 2004; McNeill et al., 2007) coupled to CIMS, as well as particle impaction based techniques, such as the TAG (Thermal Desorption Aerosol GC/MS-FID and HR-TD-PTR-MS) (Holzinger et al., 2010; Williams et al., 2006) and the MOVI (Micro Orifice Volatilization Impactor) (Yatavelli and Thornton, 2010). Thornberry et al. (2009) also operated a similar impaction system with a single jet and cooled collection plate coupled to a proton-transfer ion-trap mass spectrometer (PTRIT-MS). Electrostatic precipitator based methods such as Thermal Desorption CIMS (TDCIMS) (Voisin et al., 2003) are not subject to the same impaction limitations, discussed below, but are subject to variable charging efficiencies and can be limited to particles which are highly mobile. Common to these techniques is the use of thermal desorption (or laser desorption) of collected particles with subsequent analysis of the desorbed vapors via soft ionization and or chromatographic separation techniques such as GC/MS-FID and chemical ionization (CI).

Historically, the largest problems with impaction-based techniques are related to the particle collection efficiency, namely the loss of small particles to cut point diameter limitations, and particles that bounce after impacting the collection plate. Significant pressure drops are required to impact particles less than $\sim 150 \mathrm{~nm}$, which can then lead to loss of semi-volatiles, and thus most impaction approaches settle on collecting particles $>150 \mathrm{~nm}$ or use cooled collection stages (Thornberry et al., 2009; Williams et al., 2006; Yatavelli and Thornton, 2010). In many environmental chambers or often in the atmosphere, a significant fraction of organic aerosol mass can be below this cut point. To reduce particle bounce, humidification of the sample stream to grow the aerosol into a liquid (or gel-like) phase have been used (Williams et al., 2006). However, the humidification process possibly changes the partitioning and composition of the collected aerosol. Alternatively, applying a thin film of low volatility grease to increase the sticking efficiency of aerosol has been used (Vasiliou et al., 1999), but grease leads to contamination or interferences during the thermal analysis and typically eliminates that option for mass spectrometry applications. Impactor methods that do not humidify the sample flow or grease the impaction surface ultimately suffer from more bounce, which is variable in an unpredictable way and therefore can result in potentially large systematic errors.

The need to thermally desorb collected particle material for subsequent analysis of the vapors, common to many 
approaches discussed above, puts design constraints on the type of material used in the particle collection and desorption region. Metals are a common choice, as they are easy to heat, either resistively or by conduction, and do not deform significantly at typical operating temperatures $\left(200-300^{\circ} \mathrm{C}\right)$. However, metals are known to provide significant adsorptive sites for semi-volatile gases, especially when held at atmospherically relevant temperatures (Neuman et al., 1999). This adsorption of gases then results in a positive artifact during the thermal desorption of collected particles as heat forces the adsorbed gases off the surfaces just as it desorbs compounds from the particles. Inert coatings have been employed and developed in GC applications to make surfaces less reactive and therefore less likely to adsorb gases (Williams et al., 2006; Yatavelli et al., 2012), but these coatings tend to be most effective at elevated temperatures typical of GC operation and therefore can do little to change the transmission of semi-volatiles when kept at near ambient temperatures. Electrostatic precipitators can be designed to collect particles out of the ambient gas stream into an ultra-high purity buffer gas such as nitrogen, thereby avoiding the gas-contamination issue (Voisin et al., 2003). These designs potentially restrict the analyzable size range due to the added aerosol mobility requirement and can lead to loss of semi-volatile components during collection given that the particles are no longer in equilibrium with the ambient gases and are confounded by the equilibrium or induced charge distribution on the particles of a given diameter. Moreover, materials that are best for transmitting gases are not necessarily the same as types which are best for transmitting particles. These issues suggest that the gas analysis should be separated from the particle collection and desorption analysis to minimize cross talk between these measurements and to optimize the transmission and artifact determinations for a given phase.

We developed a novel approach that captures the evolution and molecular composition of both gas and particle components with separate optimized inlets utilizing a single chemical-ionization mass spectrometer. The Filter Inlet for Gases and AEROsols (FIGAERO) provides a simple platform for ambient air analysis using three specialized ports; one port for particle collection on a Teflon ${ }^{\circledR}$ (hereafter Teflon) filter, a second for thermal desorption of particles on the filter using a temperature-controlled ultrahigh purity (UHP) $\mathrm{N}_{2}$ stream, and a third for direct sampling of ambient air. The filter is moved between the collection and desorption ports automatically by means of a linear actuator. In this paper, we assess the capabilities of this inlet in terms of its particle collection efficiency, linearity, reproducibility, the magnitude of the instrumental background in the particle phase measurement and the associated minimum detectable concentration of an individual component. For this purpose, we coupled the FIGAERO to a highresolution time-of-flight chemical-ionization mass spectrometer (HRToF-CIMS) (Aljawhary et al., 2013; Mohr et al., 2013; Yatavelli et al., 2012) to study $\alpha$-pinene oxidation in laboratory chambers and to measure ambient air in the boreal forest of Finland. We report a wide suite of carboxylic acid containing compounds having oxygen to carbon ratios $(\mathrm{O} / \mathrm{C})$ ranging from 0.2 to $>1$ and carbon numbers from 1 to 30 . These compounds were present to some degree both in the gas phase and in the organic aerosol (OA) fraction of particles of size $0.01-1 \mu \mathrm{m}$. Particles in this size range were measured with unit collection efficiency (>99.997\%) and were analyzed by thermal desorption HRToF-CIMS, approximately hourly, while gases were measured at $1 \mathrm{~Hz}$ or faster. We discuss opportunities to infer information on volatility, partitioning, and thermal decomposition using the combined gas and particle thermal desorption data.

\section{Instrument description}

The FIGAERO is essentially a multi-port inlet manifold that operates in two distinct modes: (1) ambient air sampling with trace gas analysis during simultaneous particle collection on a PTFE filter via separate dedicated ports, and (2) temperature-programmed thermal desorption of the collected particles in UHP $\mathrm{N}_{2}$ with the detection of the desorbed vapors via a separate dedicated port. The two modes are fully automated and programmable allowing for continuous online sampling. In this section we describe the FIGAERO manifold in detail, its operation, and coupling to an HRToF-CIMS.

\subsection{FIGAERO design}

The FIGAERO was designed with the goal of measuring both gas and particle composition with minimal contamination to each phase from the other (cross contamination). Towards this end, we designed a manifold with two separate inlet and exit ports. One exit port is used for sampling and analyzing gases, and the other for sampling and analyzing vapors arising from the thermal desorption of collected aerosol. A moveable tray holding a filter is used to select between these two states. Figure 1a shows a schematic section view of the FIGAERO which is comprised of four principle components: (1) the main manifold (green) which provides the platform for connecting to the analysis instrument as well as the sampling pump; (2) the inlet plate (grey), which provides the interface to the sampling inlets; (3) the moveable tray (red), which acts as a valve and carries the primary FIGAERO particle collection filter; and (4) a particle blanking manifold which is periodically used to block particles from reaching the primary collection filter in the FIGAERO to determine filter-related background signals. Also shown for reference is the ion-molecule reaction region (IMR, grey) of the HRToFCIMS which is below the main manifold.

The main FIGAERO manifold is made entirely of PTFE to minimize gas-surface interactions and is $105 \mathrm{~mm} \times 55 \mathrm{~mm} \times 35 \mathrm{~mm}$ in size. The Teflon manifold houses a series of dynamic o-ring seals, and the two 

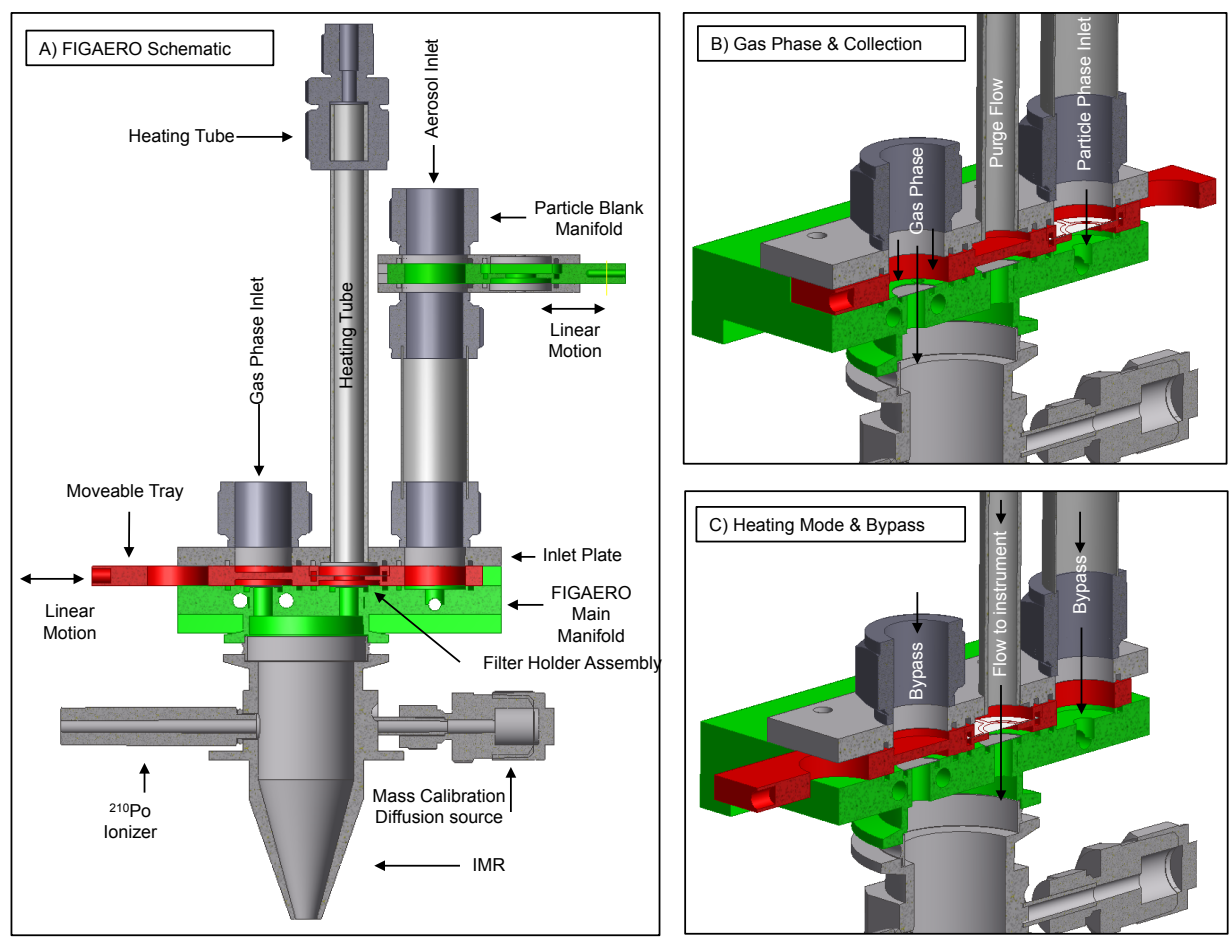

Fig. 1. FIGAERO Schematics. (A) FIGAERO section view. The main FIGAERO manifold (green), made entirely from Teflon, provides inlet and outlet connections for sampling pumps and delivery of gases to the CIMS. The HRTOF-CIMS ionization region is shown for reference below the green manifold. The moveable tray (red), also Teflon, acts as the main FIGAERO valve, and carries the PTFE filter between collection and desorption stages. The moveable tray simultaneously switches the sample flow entering the instrument between the two dedicated exit ports, one exclusively for gases, one exclusively for thermal desorptions. The inlet plate assembly (grey on top of red section) provides the interface between the FIGAERO manifold and the ambient sampling inlets. The gas analysis port is a $19 \mathrm{~mm}$ Swagelok compression fitting; the particle collection port is a $25 \mathrm{~mm}$ compression fitting. (B) A perspective section view of the FIGAERO in gas measurement and particle collection mode. The desorption orifice is blocked by the moveable tray. Black arrows show the flow paths, both into the instrument and across the filter. The gas phase flow rate is $\sim 22 \mathrm{sLpm}$, only $2 \mathrm{sLpm}$ of which enter the instrument. The particle collection inlet has a flow rate of up to $30 \mathrm{sLpm}$. (C) A perspective section view of the FIGAERO in particle analysis mode. The gas sampling orifice is blocked by the moveable tray, and the filter has been moved to the thermal desorption region of the manifold where 2 sLpm of UHP $\mathrm{N}_{2}$ are delivered across the filter. This $\mathrm{N}_{2}$ stream is programmatically heated to desorb the components from the filter. The resulting vapors are sampled through a dedicated orifice into the mass spectrometer.

selectable exit ports for chemical analysis, which in this case lead to the ionization region of the mass spectrometer, and three additional ports for connecting to sampling pumps. The selectable exit ports sit within the center of a NW40 clamp flange machined into the Teflon manifold that facilitates coupling to our mass spectrometer. A rectangular slot cut into the main manifold allows a linearly actuated tray to slide parallel to the inlet and outlet faces of the manifold and perpendicular to the flow direction. This tray is made of PTFE and houses a $24 \mathrm{~mm}$ Zefluor ${ }^{\circledR}$ PTFE filter (Pall Corp.) with a built-in filter support to reduce filter deflection during sampling and heating. The tray is moved to engage different operation modes, and to couple a specific exit port on the manifold to be sampled by the mass spectrometer.

The moveable PTFE tray is compressed against the inlet face of the main manifold by a $6 \mathrm{~mm}$ thick stainless steel plate. This plate serves as the connection point to ambient air and UHP $\mathrm{N}_{2}$ used for the temperature-programmed thermal desorption. Two Swagelok compression tube fittings for 19 and $25 \mathrm{~mm}$ (3/4 in. and $1 \mathrm{in}$.) OD tubes are welded onto opposite ends of the plate to provide an interface between sampling inlets and the FIGAERO. The $19 \mathrm{~mm}$ OD fitting is used to sample ambient air directly through the manifold for detection of gases and is bored out so that a $19 \mathrm{~mm}$ OD PTFE inlet tube can slide through the inlet plate thereby avoiding contact of gases with the stainless steel walls. The other fitting is used to draw ambient air across the Teflon filter for particle collection. In the center of the top plate, a $12.5 \mathrm{~mm}$ (1/2 in.) OD thin walled $(0.5 \mathrm{~mm}$ wall thickness $)$ stainless steel tube is socket welded and wrapped with heat tape and insulation. This tube is used to deliver heated UHP nitrogen to the PTFE filter during a temperature-programmed thermal desorption. The exterior of the stainless steel tube is temperature controlled via a MICROmega PID temperature 
controller (Omega Engineering). The interior of the heating tube is filled with steel wool to facilitate heat transfer so that the exiting gas stream temperature is uniform before passing over the filter.

\subsection{HRTOF coupling}

The FIGAERO collector was specifically designed for coupling to a HRToF-CIMS; however, it could easily be adapted to other analytical instruments. The HRToF-CIMS employed here has been described previously (Aljawhary et al., 2013; Mohr et al., 2013; Yatavelli et al., 2012). Briefly, using a Tofwerk (Tofwerk AG, Thun, Switzerland) HToF-MS with an atmospheric-pressure interface (APi), a collaboration between the University of Washington, Aerodyne Research Inc, University of California San Diego, and University of Colorado led to the development of a reduced pressure selectedion chemical-ionization mass spectrometer (Bertram et al., 2011; Yatavelli et al., 2012). The high time resolution acquisition of the entire mass spectrum and the high mass resolving power $(R>5000 \mathrm{~V}$ mode) allow for de-convolution of multiple ion compositions at a given nominal mass across the entire spectrum. The combination of mass resolving power and mass accuracy, which we find to be $10 \mathrm{ppm}$ or better when assessing the location of known ions allows the elemental composition of dominant ions to be confidently assigned up to and often beyond $400 \mathrm{Th}$.

Chemical ionization provides a sensitive and selective method of detecting various volatile and semi-volatile organic compounds (VOC and SVOC) as well as inorganic compounds. Its selectivity is largely defined by the reagent ion chosen. Herein, we show results from acetate negativeion proton transfer (Bertram et al., 2011; Veres et al., 2008; Yatavelli et al., 2012) for selective detection of organic acids, as well as Iodide adduct ionization (Aljawhary et al., 2013; Kercher et al., 2009; McNeill et al., 2007) which has been used to measure organic acids, more general oxygenated organic products as well as inorganics. Example mass spectra from $\alpha$-pinene ozonolysis using acetate as the reagent ion are shown in Fig. 2. The thermal desorption spectrum is shown in red and shifted 0.5 amu to the right for clarity; the adjacent gas phase signals are shown in black. Regions of the spectra containing well-known $\alpha$-pinene ozonolysis carboxylic acid products and trace highly oxygenated acids are shown expanded in panels $\mathrm{b}$ and $\mathrm{c}$. The excellent signal-to-noise $(\mathrm{S} / \mathrm{N})$, and low backgrounds at high mass-to-charge $(\mathrm{m} / \mathrm{Q})$ make ultra-trace gas phase components detectable and identifiable at concentrations well below $1 \mathrm{ppt}$ as discussed later.

To couple the FIGAERO to our HRToF-CIMS, we use two separate critical orifices, each of which allow $2 \mathrm{sLpm}$ to enter the mass spectrometer. The moveable tray that carries the filter and toggles orifices is designed such that each mode (gas or particle analysis) is mutually exclusive, that is, only one orifice at a time is open to the mass spectrometer. Because our ionization region is operated at a reduced pressure
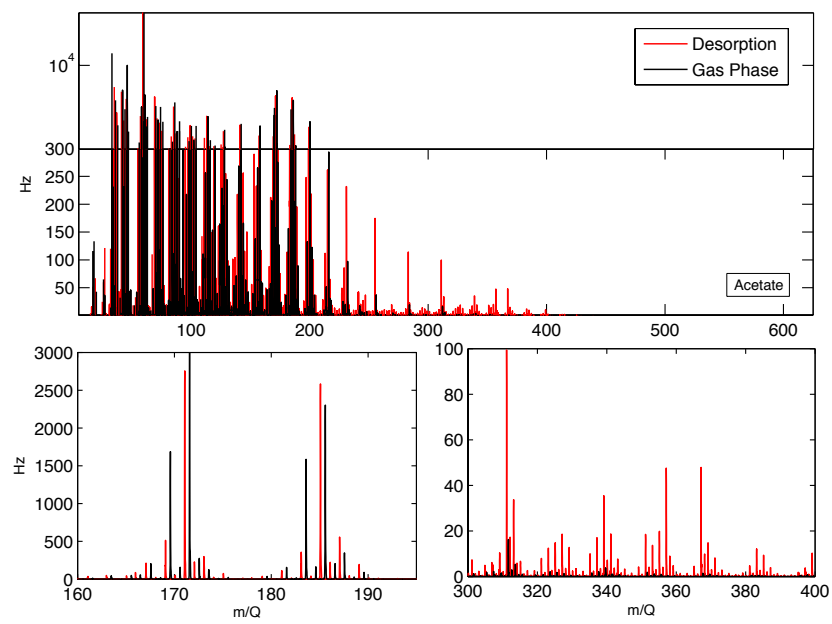

Fig. 2. Example spectra from ozonolysis of $\alpha$-pinene from the UWSeattle chamber. Thermal desorption data are shown in red, using the average desorption signal for one collection. The gas signal is shown in black shifted to the right by $0.5 \mathrm{amu}$ for clarity. The lower panels show zoomed in regions of the spectra: common major acid products from the $\alpha$-pinene + ozone reaction (left) and highly oxygenated, large molecular weight compounds which are predominantly found in the particle phase (right).

( $\sim 80$ torr), the instrument is sensitive to pressure perturbations during the switch between modes when both orifices are briefly open as the movable tray is actuated. To avoid loss of vacuum conditions in the mass spectrometer, we actively pressure control (to within \pm 0.1 torr) the ionization region (i.e., the IMR) using a servo-controlled vacuum valve upstream of the vacuum pump. As the switch begins the servocontrolled vacuum valve is actuated to the fully open position dropping the ionization region pressure to a safe level for the switch. After the switch is complete, normal operation pressures are restored.

To improve the instrument response time, we actively heat the IMR to $50-60{ }^{\circ} \mathrm{C}$. This temperature range is chosen such that particles in the gas sample stream do not efficiently volatilize and the decomposition rate of large molecular weight compounds is slow during the $\sim 100 \mathrm{~ms}$ transit through the IMR. To shield the IMR and FIGAERO from stray fields induced by heaters or other sources, we electrically connect the IMR and the FIGAERO inlet plate together to provide a uniform field in the ionization region: this voltage is typically set to ground.

\subsection{FIGAERO operation}

The operation of the FIGAERO is fully automated using a LabVIEW program. A typical sampling and filter desorption time series for various ion elemental compositions from a steady-state $\alpha$-pinene ozonolysis mixture is shown in Fig. 3 as a guide. The instrument is continuously cycled between gas (Fig. 3, "S") and particle analysis modes (Fig. 3, “TD") 


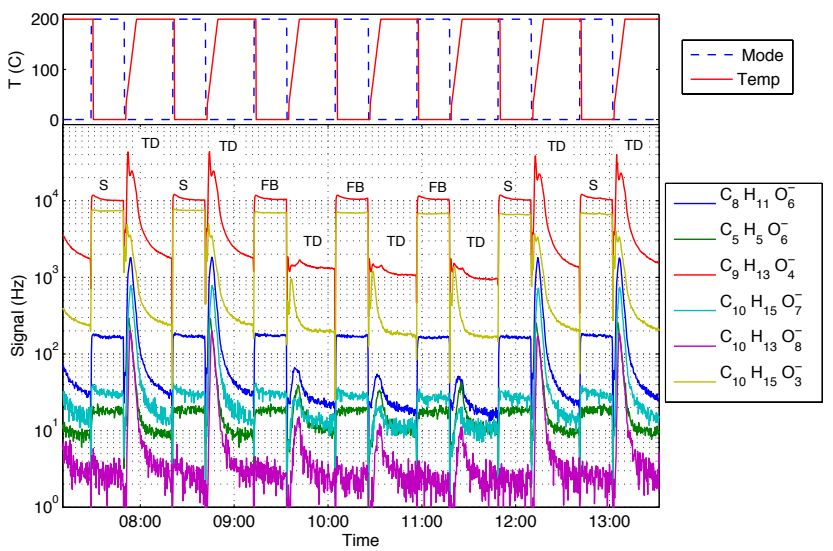

Fig. 3. The FIGAERO sampling from a steady-state chamber during performance evaluation. Top: FIGAERO manifold operational mode (blue dashed line), high during gas phase sampling and particle collection, low during thermal desorption, and UHP $\mathrm{N}_{2}$ temperature (red solid line) during thermal desorption of the collected particle samples. The temperature was ramped at $20^{\circ} \mathrm{C} \mathrm{min}^{-1}$ from room temperature to $200^{\circ} \mathrm{C}$ where it was held for $\sim 20$ additional minutes ("soak") to ensure all detectable organic material was removed from the filter. Bottom: time series of selected ion signals which span a large range in signals and $\mathrm{m} / \mathrm{Q}$, and which have different filter blank behaviors are shown during the various operational modes of the FIGAERO. Modes are denoted by text: (S) gas analysis and particle collection, (TD) thermal desorption, (FB) filter blank sampling (see text for details). The signals during TD that immediately follow the FB sampling periods represent the magnitude of the FB for a given ion composition.

with periodic determinations of the desorption signal in the absence of particles, but in the presence of gases, which we refer to as the "filter blank" and discuss in greater detail in the next sections. In Fig. 3, these filter blanks are the thermal desorptions (TD) that appear just following the sampling periods labeled "FB".

During gas analysis (Fig. 3, "S"), ambient air is sampled through a $19 \mathrm{~mm}$ OD PTFE tube at a flow rate of up to 22 sLpm (limited by the turbulence transition region). While the flow is entirely adjustable, we use large flows to optimize transmission of low volatility or "sticky" compounds, and to dilute the flux of compounds from the inlet tubing walls. The sample flow is drawn through 4 symmetrical $3.15 \mathrm{~mm}$ holes, radially arranged on the same plane as the selectable exit ports in the main PTFE manifold. The placement of these pumping holes reduces the dead volume within the manifold and allows for sampling from the centerline of the main flow. Flow through these holes is routed internally to two $6.25 \mathrm{~mm}$ ports on the external faces of the main manifold. A mass flow controller (MKS 1179a $20000 \mathrm{sccm}$ ) in line with the vacuum pump maintains the inlet flow to within $2 \%$ of the desired value and a three-way solenoid valve provides a by-pass so that the inlet tube used for detection of gases is continuously flushed when not sampled by the mass spectrometer, such as, during the particle analysis mode.
During gas analysis, ambient air is simultaneously drawn by a vacuum pump via the separate $25 \mathrm{~mm}$ OD port into the manifold and through the PTFE filter to collect aerosol particles. Upstream of the entrance port an optional $2 \mu \mathrm{m}$ impactor or cyclone is used to remove large particles prior to sampling. The large diameter conductive stainless steel tubing allows for laminar flow to be maintained up to $30 \mathrm{sLpm}$ (Reynolds number $R e=1930$ ). A large laminar particle sample flow rate shortens both inlet residence time for optimal transmission of smaller particles and the time necessary to collect sufficient mass for subsequent desorption analysis. The particle sample flow is monitored by a mass flow meter (MKS 1179a) to track the total volume sampled over the collection period.

After a predetermined time for gas phase analysis and particle collection, the switch from gas analysis to particle analysis by thermal desorption from the filter (Fig. 3, "TD") is initiated. The switching is achieved by actuating a mini linear actuator (Firgelli Technologies, L16) which slides the central tray until the filter is moved from the collection stage to the desorption stage. This process blocks the exit port used for gas phase analysis and simultaneously opens the exit port used exclusively to analyze vapor arising from the thermal desorption of material collected on the filter. By physically changing stages and exit ports, we minimize contamination of the particle-phase analysis by semi-volatiles present from the gas phase analysis that may have adsorbed to the surrounding surfaces of the manifold. That is, without moving the filter to a clean desorption region there would be a much higher non-particle background during desorptions, degrading detection limits and adding greater ambiguity to the primary phase (gas or particle) of the detected compounds.

As the switch to particle phase analysis begins, a mass flow controller delivers $2 \mathrm{sLpm}$ of UHP $\mathrm{N}_{2}$ across the filter. The flow rate across the filter is set in our application primarily by the mass spectrometer requirements. The $\mathrm{N}_{2}$ is delivered through the central "heating" tube on the manifold (see Fig. 1) which is ramped from ambient temperature up to $200^{\circ} \mathrm{C}$ at a specified ramp rate. This ramp rate sets the resolution in temperature space and amplitude of the signals detected during desorption. For example, for a given particle mass on the filter, a faster ramp rate would amplify the S / N (signal-to-noise ratio), allowing for improved detection of trace components, whereas a slower ramp rate allows for better separation of desorbing compounds in a volatility sense as the evaporation rate is proportional to the vapor pressure at a given temperature. We have empirically determined that a ramp rate between $10-50{ }^{\circ} \mathrm{C} \mathrm{min}^{-1}$ provides a good balance between these two thermogram properties ( $\mathrm{S} / \mathrm{N}$ and resolution).

After the temperature ramp is complete, the $\mathrm{N}_{2}$ stream is kept at $200^{\circ} \mathrm{C}$ for approximately $20 \mathrm{~min}$ as part of a "soak", such that signals return to near their pre-heating levels. The aim of the soak is to provide sufficient time at an elevated temperature so that all the organic material is driven from the filter and that there is not residue remaining, which could 
accumulate and contribute to the blank signals. The "soak" time is set by the typical mass loading on the filter and the volatility of the aerosol mass. Typical desorption times, including the soak period, have been on the order of 30-45 min at a ramp rate of $10-20^{\circ} \mathrm{C} \mathrm{min}^{-1}$ for both ambient and chamber studies, and can be shortened by $\sim 10$ min using a faster ramp rate. The return to gas analysis mode follows the same procedure as the switch to particle phase analysis mode, but in reverse. The full switch takes approximately $10 \mathrm{~s}$.

\subsection{Chamber and field site descriptions}

The FIGAERO has been deployed to a variety of locations for use both on laboratory chambers as well as in the field. The first application of the collector was to study $\alpha$-pinene ozonolysis at the University of Washington, followed by $\alpha$-pinene ozonolysis and photochemical $\mathrm{OH}$ oxidation at the Jülich Plant Atmosphere Chamber (JPAC, Jülich Forschungszentrum, Germany). A subsequent deployment to Hyytiälä, Finland, a monoterpene-dominated boreal forest site, provides ambient data to compare to the chamber experiments as well as evaluation of the method under field conditions. A description of each location follows below.

\subsubsection{The University of Washington chamber}

The University of Washington (UW) chamber was used for optimization and initial testing of the FIGAERO. The chamber consists of a $0.7 \mathrm{~m}^{3}$ Teflon bag with multiple sampling or fill ports. The chamber is pressure controlled by a servocontrolled valve which regulates the draw of air out of the chamber which is held slightly above atmospheric pressure. The chamber is continuously filled with zero air, generated by a Teledyne zero air generator (Model 701) and set by a $20000 \mathrm{sccm}$ MFC (MKS 1179a). $\alpha$-Pinene is delivered by a perforated Teflon diffusion tube held at room temperature and mixes with the incoming zero air which contains ozone $\left(\mathrm{O}_{3}\right)$ generated by passing $100 \mathrm{sccm}$ of UHP $\mathrm{N}_{2}$ with $10 \%$ $\mathrm{O}_{2}$ through a UV photolysis cell. The $\alpha$-pinene mass loading in the chamber is set by the flow through the diffusion tube.

\subsubsection{Jülich Plant Atmosphere chamber}

The Jülich Plant Atmosphere Chamber (JPAC) (Mentel et al., 2009) consists of a series of glass chambers housed in separate temperature controlled rooms. We used a $1450 \mathrm{~L}$ borosilicate glass chamber housed in a temperature-controlled room held at $15^{\circ} \mathrm{C}$ and relative humidity (RH) of $65 \%$. The chamber is operated under steady-state conditions and is continuously stirred by a mixer mounted at the top of the chamber. The residence time is on average $45 \mathrm{~min}$ at a flush rate of $\sim 30 \mathrm{sLpm}$. The chamber is also equipped with different types of UV lamps, one set can be used for photolysis of $\mathrm{NO}_{2}$ to $\mathrm{NO}$ and the other set of lamps for $\mathrm{OH}$ production from $\mathrm{O}_{3}$ photolysis in the presence of $\mathrm{H}_{2} \mathrm{O}$. The $\mathrm{OH}$ lamps can be shielded such that the actinic UV flux and therefore the $\mathrm{OH}$ production rate can be varied. We oxidized $\alpha$-pinene with varying concentrations of $\mathrm{O}_{3}$ and UV intensity and in the presence and absence of effloresced ammonium sulfate seed particles during a week that was part of a more extensive measurement campaign.

\subsubsection{Boreal forest site}

The FIGAERO was deployed during spring 2013 (16 April17 May) at the Station for Measuring EcosystemAtmosphere Relations II (SMEAR II) site of the University of Helsinki situated in the Hyytiälä Forestry Field Station in Hyytiälä, Finland ( $61^{\circ} 50^{\prime} 51$ in. N, $24^{\circ} 17^{\prime} 42$ in. E). The instrument was housed in a standard mobile office trailer located at the edge of a clearing of a managed 50-year-old stand dominated by Scots Pine (Pinus sylvestris). The FIGAERO inlets went straight out of the container through the roof. The FIGAERO was run continuously in the following sampling cycle: $\sim 23.5 \mathrm{sLpm}$ of outside air were drawn through the $25 \mathrm{~mm}$ (1 in.) OD stainless steel particle phase inlet (length $315 \mathrm{~cm}$, residence time $\sim 3 \mathrm{~s}$, Reynolds number $R e=1600$ ) and particles were deposited on the Teflon filter $\left(\right.$ Zefluor $^{\circledR}$ $25 \mathrm{~mm}$, pore size $1 \mu \mathrm{m}$, Pall Corp.), while also sampling ambient air through the gas analysis inlet $(19 \mathrm{~mm}(3 / 4 \mathrm{in}$.) OD Teflon (PTFE), length $320 \mathrm{~cm}, R e=2200$ ) at $22 \mathrm{sLpm}$. After each desorption we allowed the $\mathrm{N}_{2}$ gas stream passing over the filter to cool for $10 \mathrm{~min}$ to obtain a measure of instrument backgrounds. After three consecutive ambient samples, a filter blank cycle was conducted by putting another filter (Teflon $24 \mathrm{~mm}, 1 \mu \mathrm{m}$ pore size, Pall) just upstream $(\sim 30 \mathrm{~cm})$ of the FIGAERO particle filter.

\section{FIGAERO performance}

The metrics we used to assess the performance of the FIGAERO design described here are (1) gas transmission, (2) the particle collection efficiency, (3) the extent to which gas adsorption to the filter contaminates the desorption signal, (4) the reproducibility of the filter and thermal desorption process, and (5) detection limits and reliability of the inlet system.

To evaluate the FIGAERO in terms of these metrics, we used data obtained from the UW chamber where $\alpha$-pinene was reacted with excess ozone in the dark to produce semivolatile oxygenated products and SOA. A portion of this data is shown in Fig. 3. The UW chamber was run in steady state for extended periods of time (days-weeks) so that multiple samples of a given aerosol population could be measured to determine the FIGAERO reproducibility, response to changing instrument parameters, such as thermal desorption temperature ramp rates, and different manifold designs. 


\subsection{Particle collection efficiency and linearity}

The FIGAERO collection efficiency was measured with the standard $24 \mathrm{~mm}$ Zefluor $^{\circledR} 1 \mu \mathrm{m}$ pore size PTFE filters in the moveable tray of the FIGAERO collector. The FIGAERO collector, because it relies on a Teflon filter, has essentially unit collection efficiency ( $>99.997 \%$ of number), independent of particle morphology down to at least $10 \mathrm{~nm}$, the lower limit of detection for our SMPS system (TSI Model: 3080). A $2 \mu \mathrm{m}$ pore size PTFE filter of the same type had a similar collection efficiency. Thus, virtually all particles are collected by the FIGAERO without requiring perturbations to the sample flow, such as humidification to reduce bounce or for neutralizing surface charges.

An acetate quadrupole (Q-CIMS) was coupled to the FIGAERO to examine the linearity of desorption signals in response to changes in particle mass deposited on the filter. The area under a given thermogram is presumably linearly related to the mass collected and desorbed. While examining the output from the steady-state $\alpha$-pinene ozonolysis chamber, the particle collection time before each desorption was varied to change the mass loadings on the filter. The absolute mass loadings present on the filter were determined by integrating the aerosol mass concentrations measured by the SMPS over the time particles were collected on the filter. Particlefree filter blanks were done periodically during this process, employing the same collection time of the preceding sample. The filter blank desorption signals were then subtracted from the particle desorptions to obtain blank corrected particle desorption signals. The blank corrected desorption signals, shown in Fig. 4, exhibit excellent linearity with mass collected. Linear fits to the data are shown, with a median $R^{2}$ of .995 (mean $R^{2}=0.980$ ). Thus, the FIGAERO responds linearly to changes in mass on the filter across a wide spectrum of compounds.

\subsection{Instrument backgrounds, artifact determinations, and detection limits}

Instrument backgrounds arise from off-gassing of semivolatiles adsorbed to the walls of the inlet tube or IMR or from impurities in the reagent ion precursor and carrier gas. Periodically delivering UHP $\mathrm{N}_{2}$ or zero air into the ionization region provides one measure of instrumental backgrounds from that specific region. These backgrounds are subtracted from the ambient gas phase signals. Additionally, the gas phase inlet can be periodically overflowed with zero air or a subset of the flow can be drawn through a chemical scrubber to measure the inlet or isomeric or isobaric contributions to the measured ion signals. When using a long inlet line, wall collisions or evaporation from the walls will become an important sink or source, respectively, of trace gases and can thus cause slower time response or higher detection limits for low volatility compounds. For an analogous aircraft inlet system with the same flows and internal geometry as we use

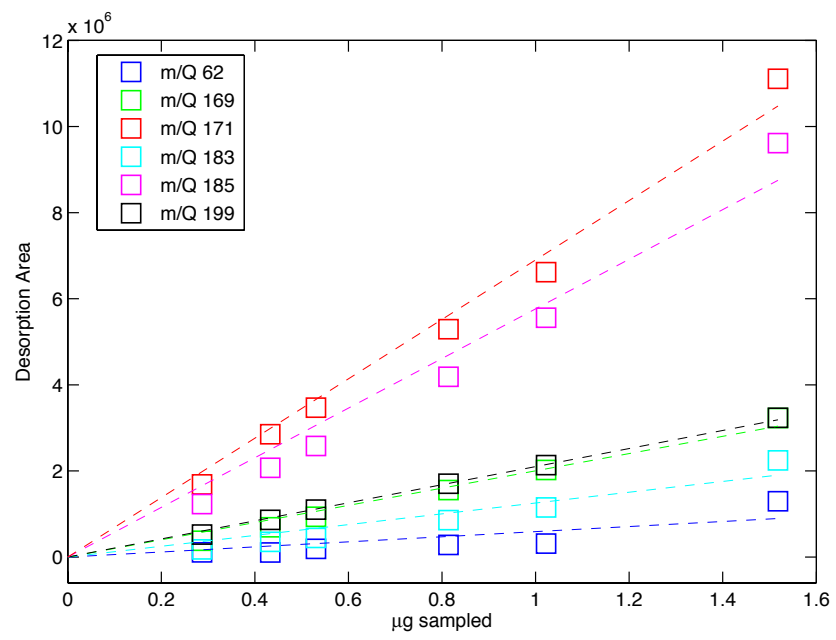

Fig. 4. Blank-corrected integrated signals measured during thermal desorption for various ion compositions plotted versus the total particle mass collected on the filter. Desorbed compounds were detected with a quadrupole CIMS employing acetate ionization coupled to the FIGAERO. To change the mass loading on the filter, particle collection times were varied while sampling from the UW steady-state $\alpha$-pinene ozonolysis chamber output. Particle mass concentrations were measured by an SMPS. Linear fits to the data forced through the origin are shown with the mean $R^{2}=0.98$.

with the FIGAERO, response times of seconds or less are attainable for intermediate volatility compounds. Memory inside the ionization region contributes to a multi-exponential response over longer timescales (minutes), the timescale of which can be adjusted by the IMR temperature. We estimate that for our ionization region temperature and residence time ( $T_{\mathrm{IMR}} 50-60^{\circ} \mathrm{C}$ and $\tau_{\mathrm{IMR}} \sim 100 \mathrm{~ms}$ ) evaporation of particle phase compounds is a relatively minor contribution to the observed gas-phase concentrations (see e.g., Yatavelli and Thornton, 2010). The coupling of the FIGAERO to detectors or ionization regions that operate at higher temperatures or longer residence times would likely result in a contamination of the gas phase signals by vaporized particles and would require different quality controls to evaluate the effect of volatilizing particles inside the instrument.

Similarly, the desorption signal is composed of that from particle-bound compounds and a non-particulate background which likely arises from gases that had adsorbed on the PTFE filter and other surfaces in the apparatus during sampling. To routinely measure this non-particulate background ("filter blank"), we developed a filter blanking manifold identical to that in the FIGAERO collector, to automatically put another PTFE filter just upstream of the FIGAERO (see Fig. 1). During a filter blank determination, ambient air is then drawn through both the "front" filter, which removes $>99.97 \%$ of entering particles but largely leaves semivolatile gases unperturbed, as well as the FIGAERO filter for the same duration as a normal particle sample collection. 
The corresponding signal from the "particle-free" desorption that immediately follows is then integrated and subtracted from the ambient particle samples to obtain a desorption signal from particles only. When not in use, a small purge flow $(\sim 100 \mathrm{sccm})$ of $150^{\circ} \mathrm{C} \mathrm{N}_{2}$ is passed across the front filter to desorb organic aerosol collected during the zeroing process.

The magnitude of these filter blanks depends on the sampling environment (chambers or polluted air versus clean remote air). They can range from nearly undetectable signals, to being equivalent to 100 s of nanograms depending on the specific compound and sampling circumstances (see, e.g., Fig. 3 for relative differences). We have found that the filter blank for a given desorbing compound is generally correlated with the gas phase concentration of that compound ( $R^{2}$ typically $\sim 0.6-0.7)$, suggesting that gases which had adsorbed to the filter and subsequently desorb during the filter heating contribute significantly to the variability in the filter blank. We attribute the peak in signal during a filter blank desorption (see, e.g., Fig. 5) to gases that had adsorbed to the filter and the baseline that the peak appears on to off-gassing from the ionization region of the mass spectrometer. The contribution of the ionization region to the total blank signal is likely to change as a function of gas loading, but with a slower timescale than the filter.

The instrument background and the ability to adequately capture its variability, whether in the gas or particle mode, ultimately set the detection limit for a given compound. We have coupled the FIGAERO to a HRToF-CIMS, which will have unique sensitivity, electronic noise, detector stability, etc. This discussion is therefore not general to all potential applications of the FIGAERO, but instead provides a guide for what likely controls the detection limits when using the FIGAERO. In terms of gas-phase compounds the factors affecting detection limits of our instrument are largely similar to any CIMS instrument as we designed the FIGAERO to be nearly indistinguishable from a standard CIMS inlet assembly. Thus, for a typical sensitivity of 30 counts s ${ }^{-1} \mathrm{ppt}^{-1}$, electronic noise $<0.1$ counts $^{-1}$, a background typical of both formic acid $\left(\sim 400\right.$ counts $\left.^{-1}\right)$ or a $\mathrm{C}_{9}$ pinene acid $\left(\sim 4\right.$ counts $\left.\mathrm{s}^{-1}\right)$, and Poisson counting statistics, a detection limit of 2 and $0.3 \mathrm{ppt}$ or less can be achieved, respectively, defined as the concentration that yields a $\mathrm{S} / \mathrm{N}$ ratio of two in $1 \mathrm{~s}$, assuming minimal interferences or inlet memory effects.

The detection limit for particle phase compounds is largely set by variability in the filter blank. To assess this variability, multiple samples were taken from the steady-state ozonolysis chamber (see Fig. 5) to measure the reproducibility at constant loadings of gases and aerosol. The variability $(1 \sigma)$ in the blank measured by the adjacent difference between over 15 determinations was approximately $2.5 \%$ of the signal for the majority of ions. We therefore take $5 \%$ to be the uncertainty in any single blank measurement. Typically, atmospheric samples are collected between filter blank determinations, and thus two blank measurements are averaged or interpolated before subtracting from the atmospheric sample.

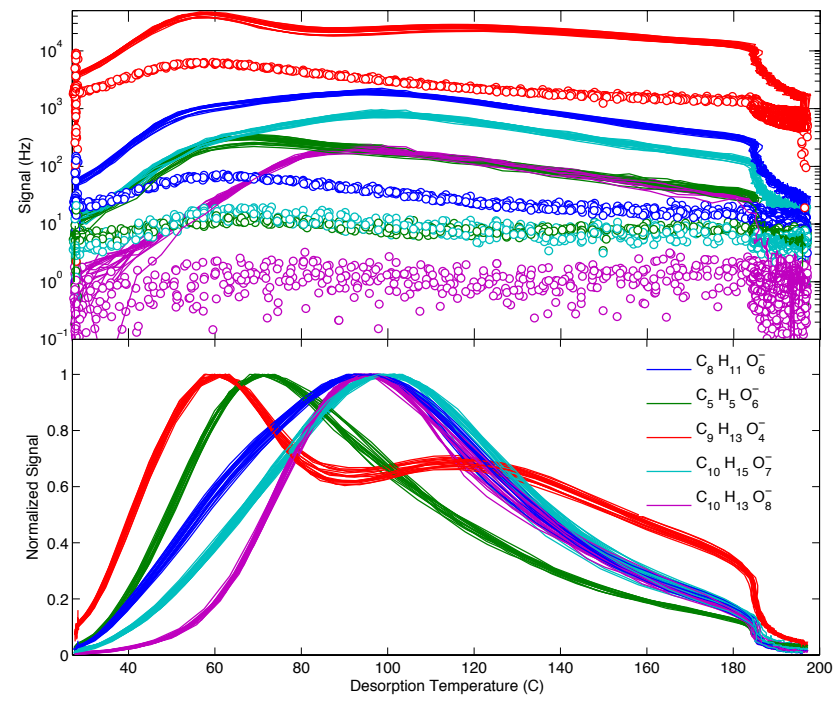

Fig. 5. Top: selected ion signals (counts per second) are plotted on a $\log$-scale versus $\mathrm{N}_{2}$ carrier gas temperature during thermal desorptions of $\alpha$-pinene ozonolysis derived organic aerosol particles (solid lines) and of corresponding filter blanks (open circles). Repeated equal duration particle collection and desorptions are shown from a 2-day period sampling from constant chamber conditions. The filter blank is factors of 10 to 100 lower than the particle-laden chamber sample depending on the specific composition of the compound. Bottom: the same particle desorption signals are shown normalized to the maximum signal on a linear scale for clarity. As temperatures near $200^{\circ} \mathrm{C}$ signals drop smoothly towards background levels during the soak period of the heating cycle. The structure of the desorptions is highly reproducible both in amplitude and temperature space. The details of the bimodal features are discussed further in the text.

The uncertainty in the blank applied to the data is then found by adding in quadrature. We define the detection limit for a particle component as $3 \times$ this uncertainty in the blank, examples of which are shown in Table 1 for compounds detected in the following ions $\mathrm{C}_{8} \mathrm{H}_{11} \mathrm{O}_{6}^{-}, \mathrm{C}_{5} \mathrm{H}_{5} \mathrm{O}_{6}^{-}, \mathrm{C}_{9} \mathrm{H}_{13} \mathrm{O}_{4}^{-}$, $\mathrm{C}_{10} \mathrm{H}_{15} \mathrm{O}_{7}^{-}, \mathrm{C}_{10} \mathrm{H}_{13} \mathrm{O}_{8}^{-}$, and $\mathrm{C}_{10} \mathrm{H}_{15} \mathrm{O}_{3}^{-}$. These are representative compounds spanning a wide range in both volatilities and the typical magnitude of signal relative to blank. Table 1 shows typical detection limits obtained while sampling on chambers and in a remote forest environment. For this purpose, ions signals were converted to mass using a formic acid sensitivity, typically of order 10 counts per second (cps) per ppt. The detection limits in the field are significantly larger than those on the steady-state chambers because larger atmospheric variability in gas-phase abundance, temperature, relative humidity, etc., induces a larger variability in the blank measurements. By tracking the blank regularly, the variability is accurately captured, and thus the detection limits are kept within a workable range.

Despite the incorporation of these quality control checks into the FIGAERO operation, care must still be taken when 
Table 1. Detection limits for two different sampling conditions: first, from the UW-Chamber (see text for operation details), second, for a 2 -week ambient data set from Hyytiälä, Finland. All species reported were detected at the deprotonated ion. Detection limits represent $3 \sigma$ confidence levels, where ion signals were converted to mass using the instrument's formic acid sensitivity. All detection limits are calculated for each blank pair and the average is reported here, with \pm 1 standard deviation. For the chamber conditions there is little temporal change, but high gas phase concentrations. In Hyytiälä, gas phase concentrations are significantly lower; however, temperatures are much colder and there is more temporal atmospheric change, resulting in higher detection limits on average. For Hyytiälä, there is also an increase in the variability of the blank, represented by the standard deviation, relative to the steady-state chamber because atmospheric variability drives relatively larger changes in the field blanks. Because of frequent determinations, we are able to capture much of that variability on the timescales of hours and are therefore able to remove the changing artifact from the data. Detection limits are also reported in pg $\mathrm{m}^{-3}$ by taking into account the volume of air sampled across the filter during particle collection which was different between the chamber and the field deployment.

\begin{tabular}{lllllll}
\hline & $\mathrm{C}_{8} \mathrm{H}_{12} \mathrm{O}_{6}$ & $\mathrm{C}_{5} \mathrm{H}_{6} \mathrm{O}_{6}$ & $\mathrm{C}_{9} \mathrm{H}_{14} \mathrm{O}_{4}$ & $\mathrm{C}_{10} \mathrm{H}_{16} \mathrm{O}_{7}$ & $\mathrm{C}_{10} \mathrm{H}_{14} \mathrm{O}_{8}$ & $\mathrm{C}_{10} \mathrm{H}_{16} \mathrm{O}_{3}$ \\
\hline UW Chamber (pg) & $3 \pm 1$ & $1 \pm 1$ & $170 \pm 61$ & $3 \pm 2$ & $1 \pm 1$ & $86 \pm 50$ \\
pg m$^{-3}$ & $35 \pm 16$ & $11 \pm 5$ & $1690 \pm 610$ & $25 \pm 15$ & $5 \pm 8$ & $860 \pm 475$ \\
Hyytiälä, Finland (pg) & $125 \pm 210$ & $130 \pm 150$ & $630 \pm 690$ & $55 \pm 90$ & $40 \pm 90$ & $160 \pm 180$ \\
pg m $^{-3}$ & $180 \pm 300$ & $180 \pm 210$ & $900 \pm 980$ & $80 \pm 130$ & $60 \pm 125$ & $230 \pm 255$ \\
\hline
\end{tabular}

interpreting the implied phase partitioning that results from the measurement of a compound in the gas and particle phase. For example a very "sticky" low volatility gas that is nearly entirely lost to a Teflon surface with near unit efficiency per collision will be measured as a particle component as it will contribute to the particle desorption signal but will have a negligible contribution to the filter blank because the front filter will scrub it. Similarly semi-volatile and volatile compounds that would normally be entirely in the gas phase can through adsorption and absorption adhere to Teflon surfaces (Matsunaga and Ziemann, 2010). We cannot distinguish between adsorption or absorption, but routinely measure the sum of them using the blanking filter. This issue is not entirely problematic because a vapor that is entirely removed by a Teflon surface is likely to partition to the particle phase. Semi-volatiles that evaporate from the filter during collection, due to a change in the ambient air concentration represent a negative bias to the particle signal. However, the continuous exposure of the collected particles to a high flow of ambient air for relatively short particle collection times ( $\sim 30 \mathrm{~min}$ ) makes this issue less of a problem compared to high-volume samples collected over 12-24 h (Turpin et al., 2000), or for particles collected at reduced pressure or in UHP $\mathrm{N}_{2}$.

\subsection{Thermal desorption reproducibility and volatility separation}

To examine the reproducibility of the thermal desorption signals, we coupled the FIGAERO to a HRToF-CIMS, operating in acetate mode, and sampled continuously from the UW steady-state $\alpha$-pinene ozonolysis system for approximately 2 days. In Fig. 5 (top panel) the particle desorption signals (lines) and corresponding particle-free filter blank signals (open symbols) are shown on a log scale for several ion compositions obtained during this 2 -day period. In the bottom panel of Fig. 5, the particle desorptions are reproduced on a linear scale for greater clarity. The integrated areas and the shapes of the desorption profiles are highly reproducible for both particle desorptions and filter blanks. With a constant collection time, ramp rate, and particle concentration, not only is the integrated desorption area the same within 5-10\% but also that the location of the maximum signal in temperature space is the same within $\sim 2{ }^{\circ} \mathrm{C}$ showing reproducibility in both absolute mass recovered and thermal behavior. This reproducibility is essential for volatility estimation and separation of desorbed aerosol components and gives confidence that the Teflon filter is robust to repeated exposure to temperatures $>200{ }^{\circ} \mathrm{C}$.

The reproducibility of the desorption profiles suggests a fundamental connection between characteristics of the desorption profile and the chemical and physical properties of the compounds in the particle phase. To examine this connection, and to facilitate the development of a representative volatility axis, we deposited mixtures of known carboxylic acid compounds on the Teflon filter, and subsequently conducted thermal desorptions with detection by Iodide adduct HRToF-CIMS. In Fig. 6a, we show the corresponding desorptions for a few representative compounds that bracket the full range of behavior from the mixture. The separation in temperature space follows the expected pattern where higher volatility compounds desorb at lower temperatures and lower volatility compounds desorb at higher temperatures. Temperature programmed thermal desorption profiles, which for pure compounds are effectively a measure of the evaporation rate and thus the temperature-dependent equilibrium vapor pressure, have been used to extract the enthalpy and entropy of vaporization of various organic aerosol surrogates (Bilde and Pandis, 2001; Cappa et al., 2008; Salo et al., 2010; Yatavelli and Thornton, 2010). In this experiment all ions show a clear and smooth monotonic peak during the desorption, signifying little contamination at those masses from 


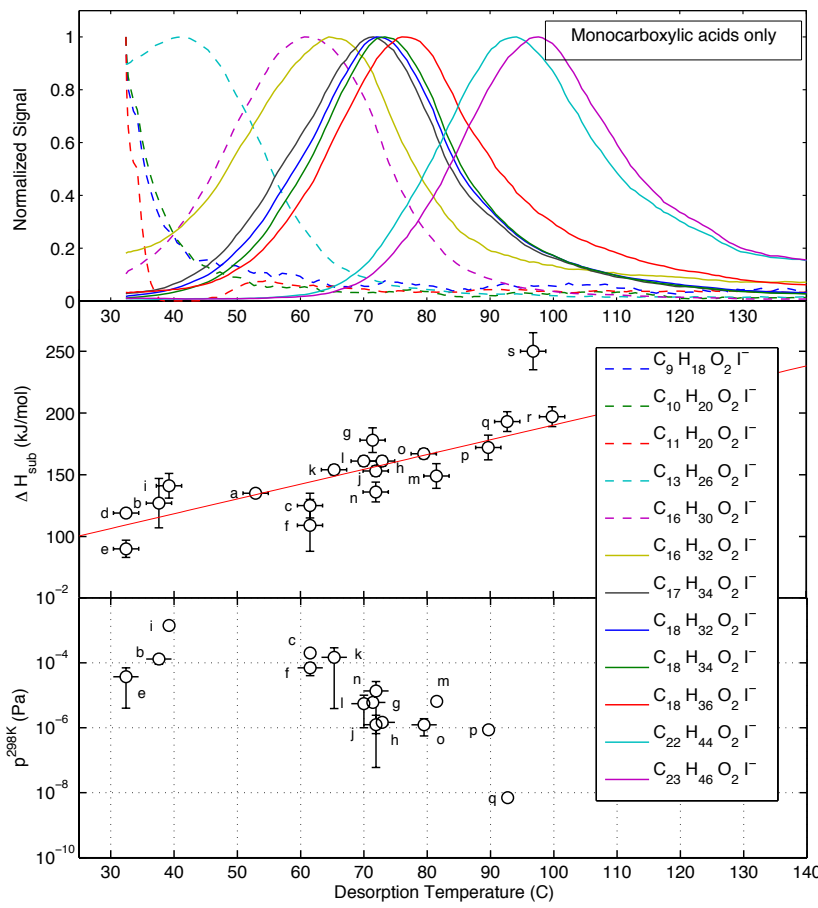

Fig. 6. Top: thermograms from a series of mono carboxylic acids are shown as detected by a FIGAERO-HRToF-CIMS operating in the field employing Iodide adduct ionization. The acids were part of a single mixture of several organic compounds that was deposited manually via a micro-syringe onto the FIGAERO filter, and then the filter was subjected to a standard thermal desorption. The series of acids each desorb with a single signal maximum (mode), signifying little contamination from other ions (see text). Middle: $\Delta H_{\text {sub }}$ values for compounds in the deposited mixture from the literature (open symbols) or estimated here using group contribution methods (dots) are plotted versus the temperature at which the compound's signal reached a maximum in the desorption $\left(T_{\max }\right.$, see text). Letters correspond to the identifier (ID) listed in Table 2. Bottom: literature vapor pressures over the solid scattered with maximum desorption temperature. The relationship is less clear than enthalpy of sublimation likely resulting from the larger relative uncertainties in the measured vapor pressures.

other interferences (discussed later). In Fig. 6b, we scatter the temperature of maximum desorption signal $\left(T_{\max }\right)$ with $\Delta H_{\text {sub }}$ in an effort to calibrate the desorption temperature axis. Letters correspond to the identifier (ID) listed in Table 2 along with the source for the literature $\Delta H_{\text {sub }}$ used in the correlation. In Fig. $6 \mathrm{c}$ we correlate $T_{\max }$ with published vapor pressures; the correlation with enthalpy of sublimation is much stronger presumably because of the smaller relative error in enthalpy determinations than for vapor pressure measurements (see Table 2).

We find an approximately linear relationship $\left(R^{2}=0.82\right)$ between the temperature at which the desorption signal for a given compound reaches a maximum $\left(T_{\max }\right)$ and the enthalpy of sublimation $\left(\Delta H_{\text {sub }}\right)$, a physical parameter useful in further developing partitioning models (Donahue et al., 2006; Epstein et al., 2010). Using the $T_{\max }$ provides an estimate of volatility that is independent of the absolute evaporation rate, which would require knowing the instrument's detection sensitivity to every compound detected.

By using known compounds with well-defined $\Delta H_{\text {sub }}$ values, and the inherent reproducibility of the desorption profiles, the volatility scale based on $T_{\max }$ can be calibrated. An effective enthalpy of "desorption" $\Delta H_{\text {eff }}$ can then be estimated for hundreds of compounds detected in the atmosphere or laboratory chamber studies. We stress that the $\Delta H_{\text {eff }}$ we obtain from mixtures of unknown contents is intrinsic to the FIGAERO process and properties of the aerosol which may or may not be obtainable by this method, and therefore is not necessarily a measure of the actual $\Delta H_{\text {sub. For }}$ example, formic acid is often detected in particle-phase desorptions. The corresponding desorption profile maximizes at high temperatures more consistent with a much lower volatility compound. This behavior suggests that its source is likely not actual formic acid which has physically partitioned to the aerosol, but rather a decomposition fragment of larger thermally unstable compounds that have a lower volatility. Nonetheless, this approach provides a physically relevant scale with which to compare compounds within a sample, or across different samples. Applying the calibrated relationship between the observed $T_{\max }$ and $\Delta H_{\text {sub }}$, we find carboxylic acids that desorb from $\alpha$-pinene SOA separate into two broad volatility bins. These two bulk bins each explain approximately half of the total desorption signal, and correspond to an $\Delta H_{\text {eff }}$ of $\sim 140 \mathrm{~kJ} \mathrm{~mol}^{-1}$ and $\sim 240 \mathrm{~kJ} \mathrm{~mol}^{-1}$.

Our method of determining $\Delta H_{\text {eff }}$ is significantly different than previous measures of the evaporation rates and volatility estimations, such as those using thermal denuder tandem differential mobility analyzers (DMAs) (Bilde and Pandis, 2001; Salo et al., 2010), making direct comparisons difficult. In our approach, the gas phase concentration of a desorbing compound arises only from that desorbed from the filter, and is continuously diluted away into the sample flow, whereas other methods can initially have high gas loadings, in addition to those generated from volatilizing the particles before being denuded (Bilde and Pandis, 2001; Salo et al., 2010). Moreover, we have a relatively slow temperature ramp, and exposure to hot nitrogen for $15 \mathrm{~min}$ or longer, whereas thermal denuders typically have residence times of less than a few tens of seconds. Finally, chemical-ionization methods such as those that we use, have an inherent selectivity (e.g., to carboxylic acids). The effective enthalpies of evaporation are then only relevant to compounds that are efficiently ionized and detected. That said, the two effective enthalpies of evaporation for carboxylic acids in $\alpha$-pinene ozonolysis SOA reported above imply that a significant fraction have much lower volatilities than consistent with common ozonolysis products such as pinonic and pinic acids or the bulk mass as inferred from thermal denuder studies (Bilde and Pandis, 2001; Salo et al., 2010). We show that, consistent 
Table 2. Compounds used to determine the relationship between $\Delta H_{\text {sub }}$ and maximum desorption temperature. Literature values were obtained from the NIST database (Chickos, 2013) or the source referenced in the table. The letters correspond to the labeled points in Fig. 6. Compounds were manually deposited on the FIGAERO primary filter and subsequently desorbed. Calculated values follow (Capouet and Müller, 2006) for evaluating the group contribution change in vapor pressure and therefore $\Delta H_{\text {sub }}$ from known compounds. For hydroxyacids the hydroxy group was added to calculate $\Delta H_{\text {sub }}$.

\begin{tabular}{|c|c|c|c|c|c|c|}
\hline ID & Comp. & Chemical name & $\Delta H_{\mathrm{sub}} \mathrm{kJ} \mathrm{mol}^{-1}$ & $T_{\max }\left({ }^{\circ} \mathrm{C}\right)$ & $p(298 \mathrm{~K}) 10^{-5} \mathrm{~Pa}$ & Source \\
\hline $\mathrm{a}$ & $\mathrm{C}_{4} \mathrm{H}_{10} \mathrm{O}_{4}$ & erythritol & $135 \pm 2$ & 52.9 & - & NIST \\
\hline $\mathrm{b}$ & $\mathrm{C}_{7} \mathrm{H}_{12} \mathrm{O}_{4}$ & pimelic acid & $127 \pm 20$ & 37.6 & $9-17$ & Salo et al. (2010) \\
\hline $\mathrm{c}$ & $\mathrm{C}_{6} \mathrm{H}_{10} \mathrm{O}_{5}$ & levoglucosan & $125 \pm 10$ & 61.5 & 20 & $\begin{array}{l}\text { May et al. (2012); } \\
\text { Oja and Suuberg (1999) }\end{array}$ \\
\hline $\mathrm{d}$ & $\mathrm{C}_{10} \mathrm{H}_{20} \mathrm{O}_{2}$ & decanoic acid & $119 \pm 2$ & $<32.4$ & 5400 & NIST (Cappa et al., 2008) \\
\hline $\mathrm{e}$ & $\mathrm{C}_{10} \mathrm{H}_{16} \mathrm{O}_{3}$ & pinonic acid & $90 \pm 7$ & $<32.4$ & $4-7$ & Salo et al. (2010) \\
\hline $\mathrm{f}$ & $\mathrm{C}_{9} \mathrm{H}_{14} \mathrm{O}_{4}$ & pinic acid & $109 \pm 21$ & 61.5 & $4-10$ & Salo et al. (2010) \\
\hline g & $\mathrm{C}_{9} \mathrm{H}_{16} \mathrm{O}_{4}$ & azelaic acid & $178 \pm 10$ & 71.4 & 0.6 & Bilde et al. (2003) \\
\hline $\mathrm{h}$ & $\mathrm{C}_{10} \mathrm{H}_{18} \mathrm{O}_{4}$ & sebacic acid & $161 \pm 4$ & 72.9 & 0.147 & NIST (Chattopadhyay and Ziemann, 2005) \\
\hline $\mathrm{i}$ & $\mathrm{C}_{13} \mathrm{H}_{26} \mathrm{O}_{2}$ & tridecylic acid & $141 \pm 10$ & 39.2 & 140 & NIST (Chattopadhyay and Ziemann, 2005) \\
\hline j & $\mathrm{C}_{12} \mathrm{H}_{22} \mathrm{O}_{4}$ & dodecanedioic acid & $153 \pm 4$ & 71.9 & $0.006-0.242$ & NIST (Chattopadhyay and Ziemann, 2005) \\
\hline $\mathrm{k}$ & $\mathrm{C}_{16} \mathrm{H}_{32} \mathrm{O}_{2}$ & hexadecanoic acid & $154 \pm 4$ & 65.3 & $0.39-29$ & NIST (Cappa et al., 2008) \\
\hline 1 & $\mathrm{C}_{14} \mathrm{H}_{26} \mathrm{O}_{4}$ & decanedioic acid & $161 \pm 4$ & 70.0 & $0.1-1$ & NIST, (Yatavelli and Thornton, 2010) \\
\hline $\mathrm{m}$ & $\mathrm{C}_{16} \mathrm{H}_{32} \mathrm{O}_{3}$ & hydroxy-hexadecanoic acid & $149 \pm 10$ & 81.5 & 0.653 & Chattopadhyay and Ziemann (2005) \\
\hline $\mathrm{n}$ & $\mathrm{C}_{18} \mathrm{H}_{32} \mathrm{O}_{2}$ & oleic acid & $136 \pm 8$ & 71.9 & $0.066-2.66$ & $\begin{array}{l}\text { Cappa et al. (2008); Chattopadhyay and } \\
\text { Ziemann (2005) }\end{array}$ \\
\hline o & $\mathrm{C}_{18} \mathrm{H}_{36} \mathrm{O}_{2}$ & octadecanoic acid & $167 \pm 4$ & 79.5 & $0.056-0.19$ & NIST (Cappa et al., 2008) \\
\hline $\mathrm{p}$ & $\mathrm{C}_{18} \mathrm{H}_{36} \mathrm{O}_{3}$ & hydroxy-stearic acid & $172 \pm 10$ & 89.7 & 0.0865 & Calc (Chattopadhyay and Ziemann, 2005) \\
\hline $\mathrm{q}$ & $\mathrm{C}_{22} \mathrm{H}_{44} \mathrm{O}_{2}$ & docosanoic acid & $193 \pm 8$ & 92.7 & $7 \times 10^{-4}$ & NIST (Chattopadhyay and Ziemann, 2005) \\
\hline $\mathrm{r}$ & $\mathrm{C}_{23} \mathrm{H}_{46} \mathrm{O}_{2}$ & tricosanoic acid & $197 \pm 8$ & 99.8 & - & Calc \\
\hline $\mathrm{s}$ & $\mathrm{C}_{22} \mathrm{H}_{42} \mathrm{O}_{3}$ & hydroxy-docosanoic acid & $250 \pm 15$ & 96.8 & - & Calc \\
\hline
\end{tabular}

with previous studies of the molecular composition of SOA, these lower volatility components are likely larger molecular weight dimers, trimers, or other oligomeric or extremely low volatility compounds which thermally decompose during desorption.

\subsection{Thermogram fitting and the role of decomposition}

The thermogram (desorption signal versus temperature) for a single compound should have a single mode, as evidenced by the profiles shown in Fig. 6 which were produced from the deposition of a mixture of known compounds to the filter. However, thermograms for individual ions in more complex SOA mixtures reveal multiple features, for example, shoulders or multiple peaks, throughout the thermal evolution of the collected samples; examples are shown in Figs. 5 and 7. To investigate the source of and thus information carried by the secondary desorption features, we applied a custom nonlinear least squares peak fitting routine. First, single-mode thermogram peaks are identified and standardized on a normalized width scale. The resulting normalized peaks are averaged to obtain a typical thermogram peak shape that presumably represents the desorption of a single component. An iterative fitting routine using the Levenberg-Marquardt algorithm for nonlinear least squares problems fits the multimodal thermograms by applying a variable number of thermogram peaks having the average desorption peak shape. The number, location and amplitude of each additional desorption peak within a thermogram are optimized to explain the total thermogram of a given ion. To allow for individual compounds having slightly different desorption profiles, the width of the typical desorption peak shape is allowed to vary by up to $30 \%$ based on fitting a range of thermograms from pure component desorptions.

Example fits of the $\mathrm{C}_{8} \mathrm{H}_{11} \mathrm{O}_{4}^{-}$thermogram are shown in Fig. 7. Under $\alpha$-pinene ozonolysis conditions, this ion displayed a bi-modal thermogram, with significant high temperature tailing compared to the typical thermogram peak shape (Fig. 7, bottom left). However, the signals within these three regimes (see Fig. 7) systematically changed in a relative sense, when $\alpha$-pinene oxidation was dominated by $\mathrm{OH}$ instead of $\mathrm{O}_{3}$ (Fig. 7, bottom right). The top panel of Fig. 7 shows a time series of the corresponding thermogram fits in each of the three integration regions. During ozonolysis, the primary and secondary thermogram peaks grow proportionally in the aerosol phase when inorganic seed concentrations are increased during steady-state $\alpha$-pinene ozonolysis conditions. However, when the UV lights are turned on, generating significant $\mathrm{OH}\left(10^{7}-10^{8} \mathrm{~cm}^{-3}\right)$, the first peak in the thermogram grows significantly relative to the second. Similar and, at times, more dramatic changes in the distribution of signal during thermograms are observed for many other ions measured in this experiment.

The multi-modal thermograms for an ion with the same elemental composition likely arise from either isomers having different volatilities or from thermal decomposition of larger molecular weight components prior to or during desorption 


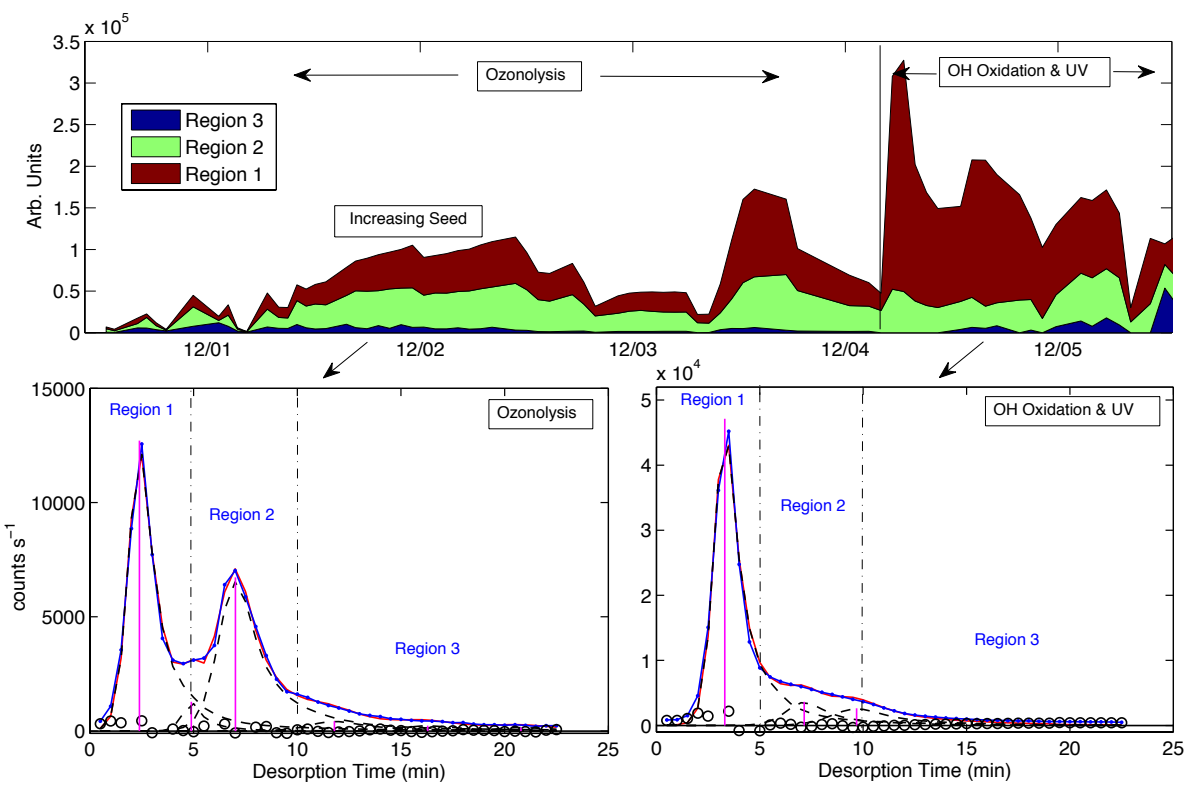

Fig. 7. An example of thermogram fitting using the $\mathrm{C}_{8} \mathrm{H}_{11} \mathrm{O}_{4}$ - desorption signal from particles collected at JPAC. Bottom left: a thermogram from $\alpha$-pinene ozonolysis is shown. The total raw signal is shown as a blue line with dots. Individual desorption peaks used to fit the total signal are shown as dashed lines with locations of the maxima indicated by vertical magenta lines. The sum of the fitted desorption peaks is shown as a red line and the residual between the signal and fitted thermogram is shown as open circles. Bottom right: a thermogram from $\alpha$-pinene oxidation by $\mathrm{OH}$ and the corresponding fits are shown - colors and symbols are the same as at the left. Although the location (in time or temperature) of the fitted desorption peaks are mostly similar for the two periods, for simplicity the fitted thermograms are divided into three regions for comparing the relative signal in the different portions of the thermogram. Top: the time series constructed from the thermogram fits using the three integration regions shown in the lower panels. Evident is the difference in absolute magnitude of the ratio of signal in Region 1 and Region 2, between ozonolysis with variable seed and $\mathrm{OH}$ oxidation, suggesting the thermograms track changes in the chemical or physical properties of the aerosol given changes in formation and processing pathways.

from the condensed phase. For the specific example of $\mathrm{C}_{8} \mathrm{H}_{11} \mathrm{O}_{4}^{-}$, the former case seems unreasonable given that there are a limited number of configurations that lead to two isomers having vapor pressures that are different by several orders of magnitude. The secondary thermogram maxima occur at higher temperature than consistent with the relationship between effective enthalpy of evaporation and composition (e.g., Fig. 6). The change in the relative contribution of the primary and secondary thermogram peaks to the total desorption signal at $\mathrm{C}_{8} \mathrm{H}_{11} \mathrm{O}_{4}^{-}$suggests that, compared to intense oxidation by $\mathrm{OH}$, ozonolysis favors the formation of a larger molecular weight compound, such as a more highly oxidized monomer, dimer, trimer, or other oligomeric compound, that can decompose into the $\mathrm{C}_{8}$ molecule. Similar multi-modal thermograms are often observed for a large number of different ion compositions spanning a large $\mathrm{m} / \mathrm{Q}$ range and average oxidation state.

Such issues are likely important for testing gas-particle partitioning theories, but they are not unique to the FIGAERO. Instead, most methods employing thermal desorption will be impacted by thermal decomposition. We find that thermal decomposition can be a significant contribution to the total desorption signal of an ion consistent with previous work (e.g., Docherty et al., 2005). In the example shown in
Fig. 7 (top), the secondary maximum can be $\sim 50 \%$ of the total signal and even higher for other ions. Decomposition can therefore lead to incorrect inferences into partitioning of semi-volatile acids if not properly addressed. With the FIGAERO we appear to be able to separate, to a first approximation, the effect of thermal decomposition by utilizing the reproducibility of the thermal desorptions and by fitting the thermograms as demonstrated above. This ability allows us to more accurately estimate partitioning, quantitatively track a contribution to particle mass that stems from compounds that do not survive thermal desorption, and develop spectral fingerprints that likely represent thermal "cracking" of these compounds. One feature that likely aids in this separation is that the FIGAERO is made entirely of Teflon (manifold and collection surface) resulting in components only loosely bound to the surface (if interacting with the surfaces at all), and thus a better separation of compounds physically adsorbed to the aerosol undergoing volatilization from those derived from decomposition is made possible. 


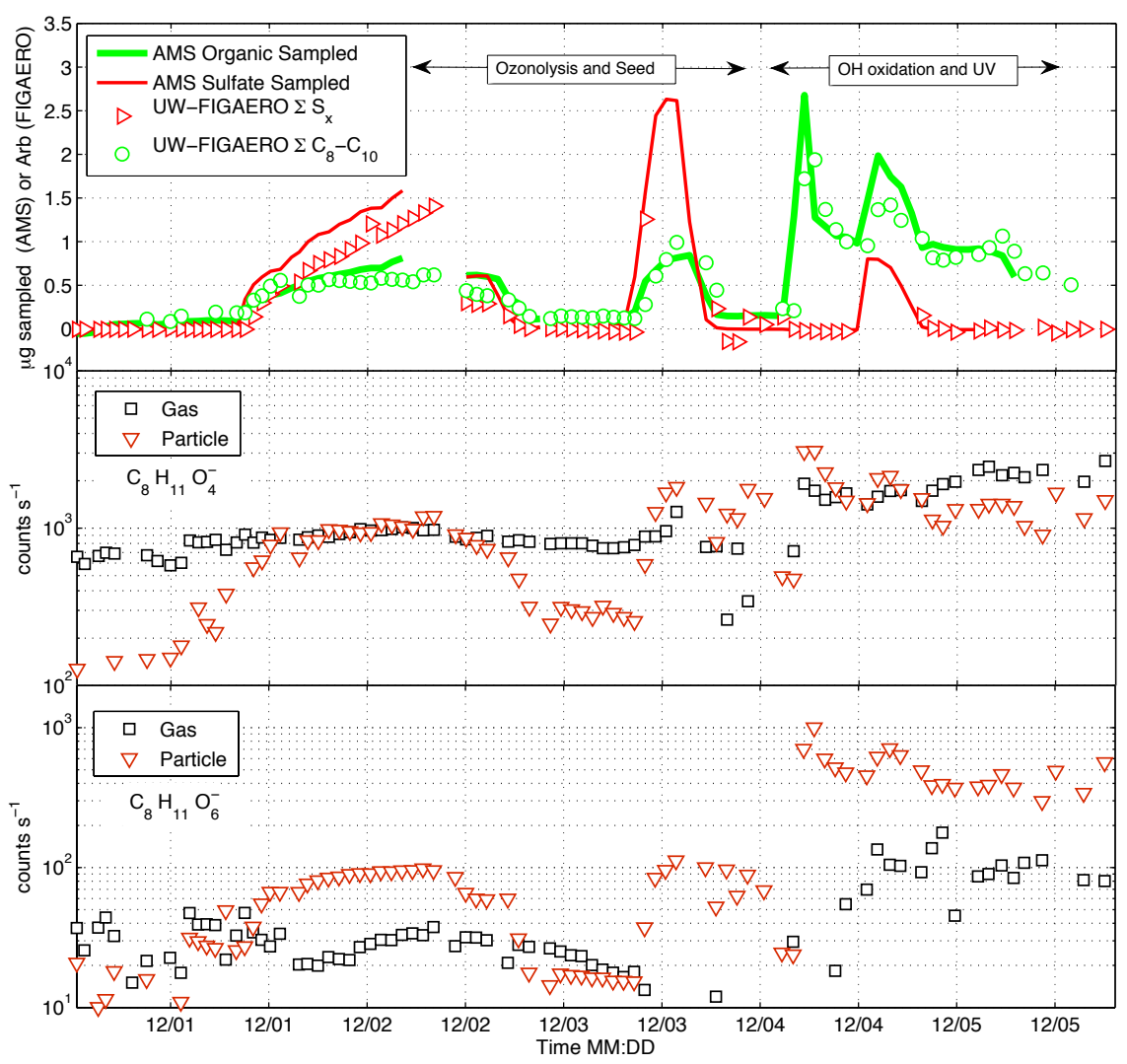

Fig. 8. A time series of the $\alpha$-pinene oxidation experiments at JPAC. Top: aerosol composition as measured by a HRToF-AMS for bulk organics as well as sulfate (thick green and thin red lines, respectively). FIGAERO data are shown as circles for both the sum of $\mathrm{C}_{8}-\mathrm{C}_{10}$ acids and of sulfur containing compounds. During the addition of ammonium sulfate seed the FIGAERO and AMS measure changes in organic aerosol loading and composition. In the lower panels, ion signals for two compounds, $\mathrm{C}_{8} \mathrm{H}_{11} \mathrm{O}_{4}^{-}$(top) and $\mathrm{C}_{8} \mathrm{H}_{11} \mathrm{O}_{6}^{-}$(bottom) are shown as measured for both gas and particle phases. The $\mathrm{C}_{8} \mathrm{H}_{11} \mathrm{O}_{6}^{-}$ion signal changes substantially during the switch from ozonolysis to $\mathrm{OH}$ oxidation. For the $\mathrm{C}_{8} \mathrm{H}_{11} \mathrm{O}_{4}^{-}$compound, the addition of seed significantly increases its detection in the particle phase, while oxidation by $\mathrm{OH}$ dampens the effect of seed on its abundance.

\section{Application to chamber and field studies and instrument comparisons}

\subsection{Jülich plant chamber experiments}

The experiments at JPAC were designed to investigate the formation of $\alpha$-pinene derived aerosol and new particle formation events. A prototype of the FIGAERO was deployed to measure aerosol composition across a wide variety of chamber conditions, including the addition of inorganic seed aerosol to $\alpha$-pinene ozonolysis products as well as varying levels of ozone, $\alpha$-pinene, and OH. $\alpha$-Pinene was added using pure diffusion sources and reacted with ozone, which was held at roughly $85 \mathrm{ppb}$. The precursor VOC concentrations were measured by a proton transfer mass spectrometer (PTRMS) (Lindinger et al., 1998) at the inlet and outlet of the chamber tracking $\alpha$-pinene reacted, which was typically $\sim 20 \mathrm{ppb}$. The chamber was run at steady state with slow changes so that the FIGAERO could take multiple samples while chamber conditions evolved and reached steady state as determined by the concentrations of aerosol mass and a wide suite of semi-volatile gas-phase products. Aerosol loadings were measured with an HRToF-AMS (DeCarlo et al., 2006) as well as SMPS (TSI Model 3080) and PSM (particle size magnifier Airmodus). The FIGAERO-HRToF-CIMS was configured for detection of carboxylic acids using acetate ionization. Iodide adduct ionization was employed towards the end of the measurement campaign. A time series of AMS organic mass concentration, and the FIGAEROHRToF-CIMS measurement of total carboxylic acid $\left(\mathrm{C}_{8}-\mathrm{C}_{10}\right.$ green circles) and sulfur-containing compounds (red squares) in the particle phase are shown in Fig. 8 (top panel). The lower panels show individual ions measured in both the gas and particle phase, and highlight the changes in aerosol composition and loading with changes in seed addition as well as the presence of $\mathrm{UV}$ radiation ( $\mathrm{OH}$ oxidation) towards the end of the week-long measurements. These individual ions show different responses from each other, in both the gas and particle phases, to the various conditions employed on the 
chamber. As hundreds of ions were tracked, there is a continuum of responses that is likely best analyzed using various statistical factorization approaches (Ulbrich et al., 2009). At all times the FIGAERO provides detailed information on the specific composition of the aerosol and is highly correlated with the organics and sulfate measured by the AMS. A more quantitative comparison that incorporates the full range of typical HRToF-CIMS sensitivities to various acids is forthcoming, but will allow direct assessment of the fraction of SOA mass that contains a carboxylic acid functionality or that develops such a functionality upon desorption.

After refinements to the prototype deployed at Jülich and further optimization of the instrument tuning, samples were taken from the UW steady-state chamber to gain sampling statistics for further evaluation of the FIGAERO manifold. Experiments were carried out at similar precursor conditions as Jülich but with no addition of seed or UV. In Fig. 9 we show the $\mathrm{O} / \mathrm{C}$ ratio versus carbon number for each ion detected, colored blue for gas phase compounds (top), by maximum desorption temperature (middle), and fraction in the particle phase (bottom), and sized by the relative contribution to particle mass based on the desorption signal and molecular weight. A large range of acidic compounds spanning $\mathrm{C}_{1}-$ $\mathrm{C}_{30}$ is produced during $\alpha$-pinene ozonolysis as detected by the FIGAERO. The fraction of a given compound measured in the particle phase (Fig. 9 (bottom)) generally follows expected trends with elemental composition, that is, larger and more highly oxygenated compounds are more strongly partitioned to the particle phase and desorb at higher temperatures. Some compounds at low carbon number stand out for desorbing only at high temperatures (Fig. 9 (middle)), and do not follow the overall trend of increasing temperature required for desorption with increasing carbon number and oxygen content. These compounds are likely decomposition fragments, which would need to be reconciled before testing against partitioning theories, as discussed in Sect. 3.3. If we assume most carboxylic acid compounds are detected with a similar sensitivity in acetate ionization, which is reasonable for more highly oxygenated compounds that tend to be present in SOA, these data imply an average $\mathrm{O} / \mathrm{C}$ of $\sim 0.6$ for $\alpha$-pinene ozonolysis SOA. This $\mathrm{O} / \mathrm{C}$ is slightly larger than most published values from AMS data, which range from $0.4-0.5$ ( $\mathrm{Ng}$ et al., 2010), though is likely consistent to within the uncertainty of both methods especially given a weighting of our approach towards carboxylic acid compounds.

\subsection{Ambient data at Hyytiälä}

The remote field site at Hyytiälä located in a boreal forest allows the study of new particle formation events and provides a strong test case for ambient measurements with the FIGAERO-HRToF-CIMS given the typically low organic aerosol loadings and photochemical activity of spring time in this region.

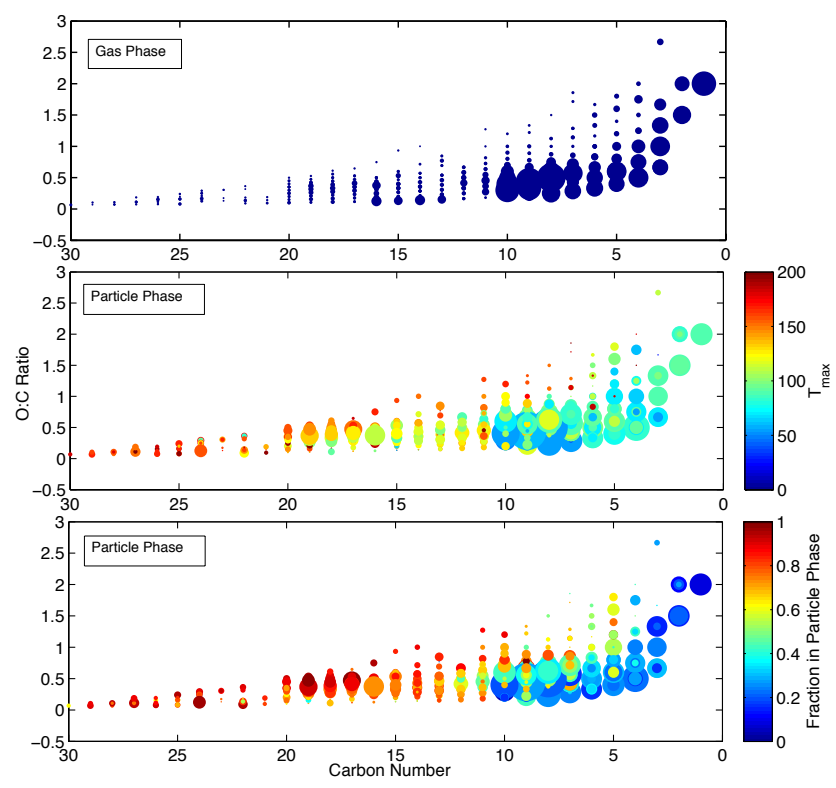

Fig. 9. The oxygen to carbon ratio $(\mathrm{O} / \mathrm{C})$ plotted versus carbon number for ions detected in the gas and particle phases when sampling from the UW Chamber under $\alpha$-pinene ozonolysis conditions. In each panel the points are sized by the square root of the mass concentration. Top: compositions for a suite of compounds measured in the gas-phase. Maximum mass concentrations are measured at compounds with less than 10 carbons. Middle: composition measured during thermal desorptions of collected particles, colored by the temperature at which the desorption signal reaches a maximum. Compounds with increasing carbon number and oxygen content generally require higher temperature to desorb. However, thermal decomposition is evident at low carbon numbers where compounds desorb at relatively higher temperatures. Bottom: as in the middle panel, except colored by the fraction of mass measured in the particle phase. Generally, increasing carbon number and oxygen content in a detected compound is associated with a greater partitioning to the particle phase.

The instrument operated nearly continuously for 3.5 weeks, with most interruptions related to power outages. Acetate ionization was employed for most of the deployment, with a short time at the end of the period spent using Iodide adduct ionization. Figure 10 summarizes some performance metrics and initial results from this deployment. In the upper left panel, we show 2 days of both ambient air signals and background determinations for $\mathrm{CHO}_{2}^{-}$and $\mathrm{C}_{10} \mathrm{H}_{15} \mathrm{O}_{3}^{-}$, which we attribute to formic acid and a monoterpene derived acid, most likely pinonic acid. Both the $\mathrm{C}_{1}$ and the $\mathrm{C}_{10}$ compounds continually exhibit a significant signal above background. In the upper right panel, we show 1 day of raw filter desorption data for $\mathrm{C}_{8} \mathrm{H}_{11} \mathrm{O}_{4}^{-}$and $\mathrm{C}_{9} \mathrm{H}_{13} \mathrm{O}_{4}^{-}$, which represent two of the more abundant ion compositions measured in the particle phase. Three ambient desorptions were followed by a filter blank desorption (described above). Even though particle mass loadings were generally low, the integrated ambient desorption signals are higher than the variability in the 

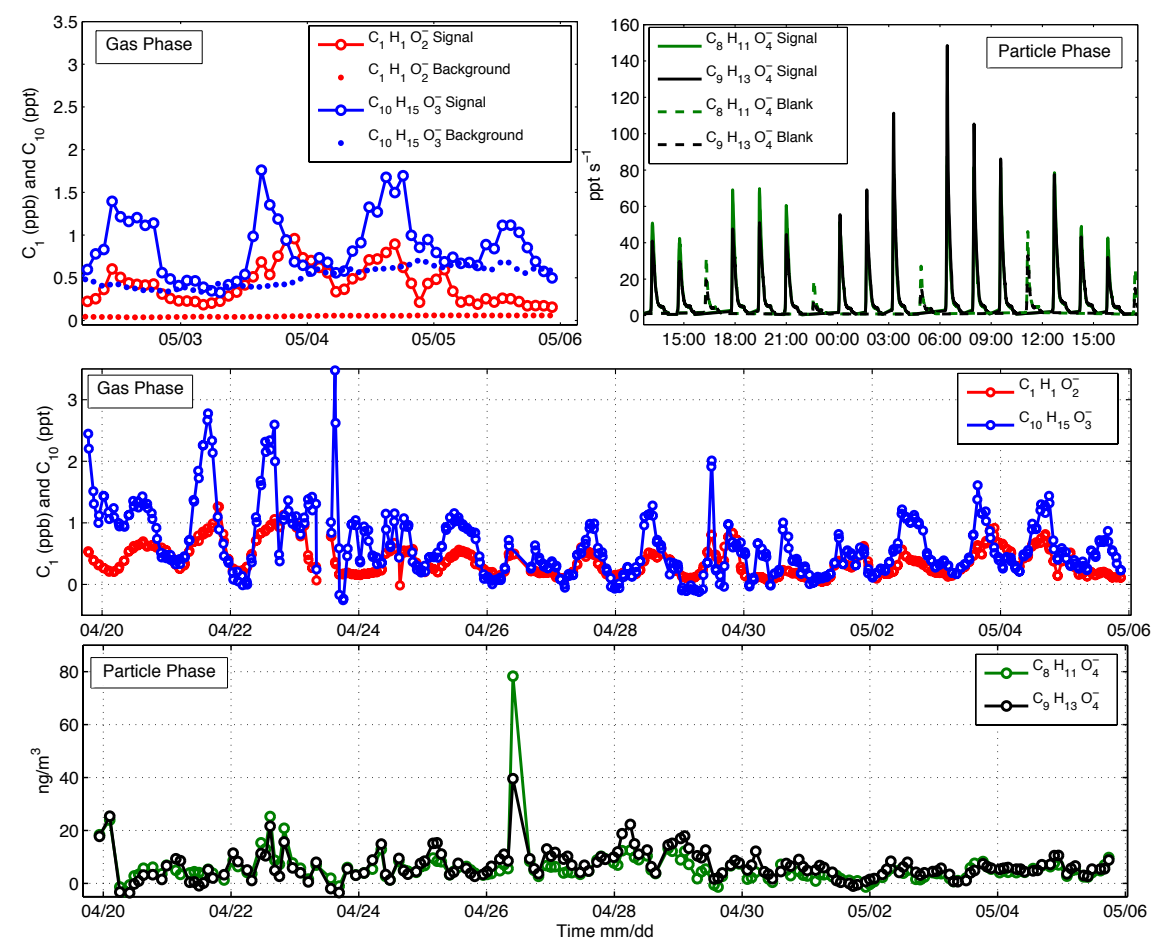

Fig. 10. An overview of the FIGAERO performance during a field campaign at Hyytiälä, Finland, a boreal forest site. Top (left): example time series of both the total signal (open circles) and measured background (dots), in mixing ratio equivalent units, for the deprotonated ions of two compounds detected in the gas phase, $\mathrm{HCOOH}$ (formic acid) and $\mathrm{C}_{10} \mathrm{H}_{16} \mathrm{O}_{3}$ (pinonic acid or other monoterpene derived acid). Significant signal above the background is measured, allowing routine measurement of sub ppt concentrations. Top (right): raw thermal desorption signals (solid lines) and filter blank determinations (dashed lines) for two major particle components in the FIGAERO HRToFCIMS spectra during measurements at the Hyytiälä field site. Filter blank desorptions are significantly lower than those containing ambient particles, allowing measurement of individual components present in particles at $1 \mathrm{ng} \mathrm{m}^{-3}$ concentrations. Middle: a time series of the background corrected $\mathrm{C}_{1}$ and $\mathrm{C}_{10}$ compounds displayed in the upper left panel, exhibiting a semi-regular diurnal pattern. Bottom: a time series of filter blank corrected particle composition. Evident is the spike in concentrations on the 26th when a sawmill plume was intercepted at the field site, otherwise the time series shows the influence of regional transport, rain events, and other meteorological influences.

integrated blank desorption signals. In the middle panel, we show the time series of ionic compositions consistent with formic acid and pinonic acid (or a similar monoterpene derived acid) as measured in the gas-phase. Ion count rates were converted to mixing ratios using the sensitivity to formic acid determined continuously on site with a C-13 labeled formic acid permeation tube. Pre- and post-campaign laboratory calibrations confirmed a similar sensitivity to pinonic acid. These two compounds represent the single largest concentration of organic acid (formic), often reaching $\sim 1 \mathrm{ppbv}$ at this site, and a typical monoterpene ozonolysis derived acid which reaches a maxima of only a few pptv. Other monoterpene acid tracers were typically of similar or lower concentrations in the gas phase. The $\mathrm{CHO}_{2}^{-}$and $\mathrm{C}_{10} \mathrm{H}_{15} \mathrm{O}_{3}^{-}$ both exhibited a strong diurnal profile with afternoon maxima which is consistent with a source driven by daytime oxidants and biogenic emissions. In the bottom panel, we show the time series of two ionic compositions, $\mathrm{C}_{8} \mathrm{H}_{11} \mathrm{O}_{4}^{-}$and $\mathrm{C}_{9} \mathrm{H}_{13} \mathrm{O}_{4}^{-}$, measured in the particle phase. These two compositions are consistent with either norpinic or terpenyllic acids and pinic acid, respectively, and typically comprised a significant fraction $(>10 \%)$ of the signal detected during desorptions. The particle-phase components have a relatively more muted diurnal cycle than the gas-phase compounds discussed above, likely representing more regionally unified sources, sinks, and distribution of organic aerosol. Minima in the time series often correspond to strong rain events, and the single maximum shown corresponds to a brief period when the site received air influenced by a nearby sawmill - a welldocumented point source for monoterpene derived aerosol at this site (Liao et al., 2011).

\section{Conclusions}

We present a novel inlet for measuring both gas and particle composition at a molecular level. While by no means free of artifacts, it provides a platform, which directly measures the dominant artifacts contributing to aerosol desorptions by gases. By coupling the FIGAERO to a HRToF-CIMS, we are able to report molecular formulas for detected compounds as 
well as partitioning related volatility measurements. Further work determining the remaining sources of blank signals will remain an important step towards lowering detection limits and improving measurement reproducibility; however, in its current state the FIGAERO is well suited for both chamber measurements as well as measurements in remote locations where organic aerosol and gas loadings are low. The FIGAERO thermograms provide additional insight into the role of thermal decomposition and add an additional degree of separation to the aerosol composition data, which until now has remained unexplored with negative-ion HRTOF-CIMS. Further application of the FIGAERO to chambers as well as ambient measurement campaigns will help improve models by increasing our understanding of OA composition as well as volatility and partitioning.

Acknowledgements. The authors would like to acknowledge D. Covert (University of Washington) for helpful discussions and careful reading of the text. We would also like to thank the supporting staff and scientists at Jülich as well as T. Petäjä and everyone at Hyytiälä for their support. We would like to thank G. Isaacman and A. Goldstein (UC, Berkeley) for sharing a calibration standard during the SOAS field project. This work was supported by the US Department of Energy through awards from the Atmospheric System Research (DE-SC0006036 and DE-SC0006867) and SBIR (DE-SC0004577) programs.

Edited by: J. Curtius

\section{References}

Aljawhary, D., Lee, A. K. Y., and Abbatt, J. P. D.: High-resolution chemical ionization mass spectrometry (ToF-CIMS): application to study SOA composition and processing, Atmos. Meas. Tech., 6, 3211-3224, doi:10.5194/amt-6-3211-2013, 2013.

Bertram, T. H., Kimmel, J. R., Crisp, T. A., Ryder, O. S., Yatavelli, R. L. N., Thornton, J. A., Cubison, M. J., Gonin, M., and Worsnop, D. R.: A field-deployable, chemical ionization timeof-flight mass spectrometer, Atmos. Meas. Tech., 4, 1471-1479, doi:10.5194/amt-4-1471-2011, 2011.

Bilde, M. and Pandis, S. N.: Evaporation Rates and Vapor Pressures of Individual Aerosol Species Formed in the Atmospheric Oxidation of $\alpha$ - and $\beta$-Pinene, Environ. Sci. Technol., 35, 3344-3349, doi:10.1021/es001946b, 2001.

Bilde, M., Svenningsson, B., Mønster, J., and Rosenørn, T.: EvenOdd Alternation of Evaporation Rates and Vapor Pressures of C3-C9 Dicarboxylic Acid Aerosols, Environ. Sci. Technol., 37, 1371-1378, doi:10.1021/es0201810, 2003.

Canagaratna, M. R., Jayne, J. T., Jimenez, J. L., Allan, J. D., Alfarra, M. R., Zhang, Q., Onasch, T. B., Drewnick, F., Coe, H., Middlebrook, A., Delia, A., Williams, L. R., Trimborn, A. M., Northway, M. J., DeCarlo, P. F., Kolb, C. E., Davidovits, P., and Worsnop, D. R.: Chemical and microphysical characterization of ambient aerosols with the aerodyne aerosol mass spectrometer, Mass Spectrom. Rev., 26, 185-222, doi:10.1002/mas.20115, 2007.
Capouet, M. and Müller, J.-F.: A group contribution method for estimating the vapour pressures of $\alpha$-pinene oxidation products, Atmos. Chem. Phys., 6, 1455-1467, doi:10.5194/acp-6-1455-2006, 2006.

Cappa, C. D., Lovejoy, E. R., and Ravishankara, A. R.: Evaporation Rates and Vapor Pressures of the Even-Numbered C 8-C 18Monocarboxylic Acids, J. Phys. Chem. A, 112, 3959-3964, doi:10.1021/jp710586m, 2008.

Chattopadhyay, S. and Ziemann, P. J.: Vapor Pressures of Substituted and Unsubstituted Monocarboxylic and Dicarboxylic Acids Measured Using an Improved Thermal Desorption Particle Beam Mass Spectrometry Method, Aerosol Sci. Tech., 39, 1085-1100, doi:10.1080/02786820500421547, 2005.

Chickos, J. S.: "Heat of Sublimation Data" in NIST Chemistry WebBook, NIST Standard Reference Database Number 69, edited by: Linstrom, P. J. and Mallard, W. G., National Institute of Standards and Technology, Gaithersburg MD, 20899, available at: http://webbook.nist.gov, last access: 26 September 2013.

Davidson, C. I., Phalen, R. F., and Solomon, P. A.: Airborne Particulate Matter and Human Health: A Review, Aerosol Sci. Tech., 39, 737-749, doi:10.1080/02786820500191348, 2005.

DeCarlo, P. F., Kimmel, J. R., Trimborn, A., Northway, M. J., Jayne, J. T., Aiken, A. C., Gonin, M., Fuhrer, K., Horvath, T., Docherty, K. S., Worsnop, D. R., and Jimenez, J. L.: Field-Deployable, High-Resolution, Time-of-Flight Aerosol Mass Spectrometer, Anal. Chem., 78, 8281-8289, doi:10.1021/ac061249n, 2006.

Docherty, K. S., Wu, W., Lim, Y. B., and Ziemann, P. J.: Contributions of Organic Peroxides to Secondary Aerosol Formed from Reactions of Monoterpenes with $\mathrm{O}_{3}$, Environ. Sci. Technol., 39, 4049-4059, doi:10.1021/es050228s, 2005.

Donahue, N. M., Robinson, A. L., Stanier, C. O. and Pandis, S. N.: Coupled Partitioning, Dilution, and Chemical Aging of Semivolatile Organics, Environ. Sci. Technol., 40(8), 26352643, doi:10.1021/es052297c, 2006.

Epstein, S. A., Riipinen, I., and Donahue, N. M.: A Semiempirical Correlation between Enthalpy of Vaporization and Saturation Concentration for Organic Aerosol, Environ. Sci. Technol., 44, 743-748, doi:10.1021/es902497z, 2010.

Gard, E., Mayer, J. E., Morrical, B. D., Dienes, T., Fergenson, D. P., and Prather, K. A.: Real-Time Analysis of Individual Atmospheric Aerosol Particles: Design and Performance of a Portable ATOFMS, Anal. Chem., 69, 4083-4091, doi:10.1021/ac970540n, 1997.

Hallquist, M., Wenger, J. C., Baltensperger, U., Rudich, Y., Simpson, D., Claeys, M., Dommen, J., Donahue, N. M., George, C., Goldstein, A. H., Hamilton, J. F., Herrmann, H., Hoffmann, T., Iinuma, Y., Jang, M., Jenkin, M. E., Jimenez, J. L., Kiendler-Scharr, A., Maenhaut, W., McFiggans, G., Mentel, Th. F., Monod, A., Prévôt, A. S. H., Seinfeld, J. H., Surratt, J. D., Szmigielski, R., and Wildt, J.: The formation, properties and impact of secondary organic aerosol: current and emerging issues, Atmos. Chem. Phys., 9, 5155-5236, doi:10.5194/acp-9-51552009, 2009.

Hearn, J. D. and Smith, G. D.: A Chemical Ionization Mass Spectrometry Method for the Online Analysis of Organic Aerosols, Anal. Chem., 76, 2820-2826, doi:10.1021/ac049948s, 2004.

Holzinger, R., Kasper-Giebl, A., Staudinger, M., Schauer, G., and Röckmann, T.: Analysis of the chemical composition of organic aerosol at the Mt. Sonnblick observatory using a novel 
high mass resolution thermal-desorption proton-transfer-reaction mass-spectrometer (hr-TD-PTR-MS), Atmos. Chem. Phys., 10, 10111-10128, doi:10.5194/acp-10-10111-2010, 2010.

Jayne, J. T., Leard, D. C., Zhang, X., Davidovits, P., Smith, K. A., Kolb, C. E. and Worsnop, D. R.: Development of an Aerosol Mass Spectrometer for Size and Composition Analysis of Submicron Particles, Aerosol Sci. Technol., 33, 49-70, doi:10.1080/027868200410840, 2000.

Jimenez, J. L., Canagaratna, M. R., Donahue, N. M., Prevot, A. S. H., Zhang, Q., Kroll, J. H., DeCarlo, P. F., Allan, J. D., Coe, H., Ng, N. L., Aiken, A. C., Docherty, K. S., Ulbrich, I. M., Grieshop, A. P., Robinson, A. L., Duplissy, J., Smith, J. D., Wilson, K. R., Lanz, V. A., Hueglin, C., Sun, Y. L., Tian, J., Laaksonen, A., Raatikainen, T., Rautiainen, J., Vaattovaara, P., Ehn, M., Kulmala, M., Tomlinson, J. M., Collins, D. R., Cubison, M. J., E., Dunlea, J., Huffman, J. A., Onasch, T. B., Alfarra, M. R., Williams, P. I., Bower, K., Kondo, Y., Schneider, J., Drewnick, F., Borrmann, S., Weimer, S., Demerjian, K., Salcedo, D., Cottrell, L., Griffin, R., Takami, A., Miyoshi, T., Hatakeyama, S., Shimono, A., Sun, J. Y., Zhang, Y. M., Dzepina, K., Kimmel, J. R., Sueper, D., Jayne, J. T., Herndon, S. C., Trimborn, A. M., Williams, L. R., Wood, E. C., Middlebrook, A. M., Kolb, C. E., Baltensperger, U., and Worsnop, D. R.: Evolution of Organic Aerosols in the Atmosphere, Science, 326, 1525-1529, doi:10.1126/science.1180353, 2009.

Kercher, J. P., Riedel, T. P., and Thornton, J. A.: Chlorine activation by $\mathrm{N}_{2} \mathrm{O}_{5}$ : simultaneous, in situ detection of $\mathrm{ClNO}_{2}$ and $\mathrm{N}_{2} \mathrm{O}_{5}$ by chemical ionization mass spectrometry, Atmos. Meas. Tech., 2, 193-204, doi:10.5194/amt-2-193-2009, 2009.

Kroll, J. H., Donahue, N. M., Jimenez, J. L., Kessler, S. H., Canagaratna, M. R., Wilson, K. R., Altieri, K. E., Mazzoleni, L. R., Wozniak, A. S., Bluhm, H., Mysak, E. R., Smith, J. D., Kolb, C. E., and Worsnop, D. R.: Carbon oxidation state as a metric for describing the chemistry of atmospheric organic aerosol, Nat. Chem., 3, 133-139, doi:10.1038/nchem.948, 2011.

Lake, D. A., Tolocka, M. P., Johnston, M. V., and Wexler, A. S.: Mass Spectrometry of Individual Particles between 50 and $750 \mathrm{~nm}$ in Diameter at the Baltimore Supersite, Environ. Sci. Technol., 37, 3268-3274, doi:10.1021/es026270u, 2003.

Liao, L., Dal Maso, M., Taipale, R., Rinne, J., Ehn, M., Junninen, H., ÄIJÄLÄ, M., Nieminen, T., Alekseychik, P., and Hulkkonen, M.: Monoterpene pollution episodes in a forest environment: indication of anthropogenic origin and association with aerosol particles, Boreal Environ. Res., 16, 288-303, 2011.

Lindinger, W., Hansel, A., and Jordan, A.: On-line monitoring of volatile organic compounds at pptv levels by means of protontransfer-reaction mass spectrometry (PTR-MS) medical applications, food control and environmental research, Int. J. Mass Spectrom., 173, 191-241, doi:10.1016/S0168-1176(97)00281-4, 1998.

Matsunaga, A. and Ziemann, P. J.: Gas-Wall Partitioning of Organic Compounds in a Teflon Film Chamber and Potential Effects on Reaction Product and Aerosol Yield Measurements, Aerosol Sci. Technol., 44, 881-892, doi:10.1080/02786826.2010.501044, 2010.

May, A. A., Saleh, R., Hennigan, C. J., Donahue, N. M., and Robinson, A. L.: Volatility of organic molecular markers used for source apportionment analysis: measurements and implications for atmospheric lifetime, Environ. Sci. Technol., 46, 1243512444, doi:10.1021/es302276t, 2012.

McKeown, P. J., Johnston, M. V., and Murphy, D. M.: On-line single-particle analysis by laser desorption mass spectrometry, Anal. Chem., 63, 2069-2073, 1991.

McNeill, V. F., Wolfe, G. M., and Thornton, J. A.: The Oxidation of Oleate in Submicron Aqueous Salt Aerosols: Evidence of a Surface Process, J. Phys. Chem. A, 111, 1073-1083, doi:10.1021/jp066233f, 2007.

Mentel, Th. F., Wildt, J., Kiendler-Scharr, A., Kleist, E., Tillmann, R., Dal Maso, M., Fisseha, R., Hohaus, Th., Spahn, H., Uerlings, R., Wegener, R., Griffiths, P. T., Dinar, E., Rudich, Y., and Wahner, A.: Photochemical production of aerosols from real plant emissions, Atmos. Chem. Phys., 9, 4387-4406, doi:10.5194/acp9-4387-2009, 2009.

Mohr, C., Lopez-Hilfiker, F. D., Zotter, P., Prévôt, A. S. H., Xu, L., Ng, N. L., Herndon, S. C., Williams, L. R., Franklin, J. P., Zahniser, M. S., Worsnop, D. R., Knighton, W. B., Aiken, A. C., Gorkowski, K. J., Dubey, M. K., Allan, J. D., and Thornton, J. A.: Contribution of Nitrated Phenols to Wood Burning Brown Carbon Light Absorption in Detling, United Kingdom during Winter Time, Environ. Sci. Technol., 47, 6316-6324, doi:10.1021/es400683v, 2013.

Neuman, J. A., Huey, L. G., Ryerson, T. B., and Fahey, D. W.: Study of Inlet Materials for Sampling Atmospheric Nitric Acid, Environ. Sci. Technol., 33, 1133-1136, doi:10.1021/es980767f, 1999.

Ng, N. L., Canagaratna, M. R., Zhang, Q., Jimenez, J. L., Tian, J., Ulbrich, I. M., Kroll, J. H., Docherty, K. S., Chhabra, P. S., Bahreini, R., Murphy, S. M., Seinfeld, J. H., Hildebrandt, L., Donahue, N. M., DeCarlo, P. F., Lanz, V. A., Prévôt, A. S. H., Dinar, E., Rudich, Y., and Worsnop, D. R.: Organic aerosol components observed in Northern Hemispheric datasets from Aerosol Mass Spectrometry, Atmos. Chem. Phys., 10, 46254641, doi:10.5194/acp-10-4625-2010, 2010.

Oja, V. and Suuberg, E. M.: Vapor Pressures and Enthalpies of Sublimation of d-Glucose, d-Xylose, Cellobiose, and Levoglucosan, J. Chem. Eng. Data, 44, 26-29, doi:10.1021/je980119b, 1999.

Pankow, J. F.: An absorption model of the gas/aerosol partitioning involved in the formation of secondary organic aerosol, Atmos. Environ., 41, 75-79, doi:10.1016/j.atmosenv.2007.10.060, 2007.

Pope III, C. A. and Dockery, D. W.: Health Effects of Fine Particulate Air Pollution: Lines that Connect, J. Air Waste Manage., 56, 709-742, doi:10.1080/10473289.2006.10464485, 2006.

Saarnio, K., Teinilä, K., Saarikoski, S., Carbone, S., Gilardoni, S., Timonen, H., Aurela, M., and Hillamo, R.: Online determination of levoglucosan in ambient aerosols with particle-into-liquid sampler - high-performance anion-exchange chromatography mass spectrometry (PILS-HPAEC-MS), Atmos. Meas. Tech., 6, 2839-2849, doi:10.5194/amt-6-2839-2013, 2013.

Salo, K., Jonsson, A. M., Andersson, P. U., and Hallquist, M.: Aerosol Volatility and Enthalpy of Sublimation of Carboxylic Acids, J. Phys. Chem. A, 114, 4586-4594, doi:10.1021/jp910105h, 2010.

Thomson, D. S., Schein, M. E., and Murphy, D. M.: Particle Analysis by Laser Mass Spectrometry WB-57F Instrument Overview, Aerosol Sci. Technol., 33, 153-169, doi:10.1080/027868200410903, 2000.

Thornberry, T., Murphy, D. M., Thomson, D. S., de Gouw, J., Warneke, C., Bates, T. S., Quinn, P. K., and Coffman, D.: 
Measurement of Aerosol Organic Compounds Using a Novel Collection/Thermal-Desorption PTR-ITMS Instrument, Aerosol Sci. Technol., 43, 486-501, doi:10.1080/02786820902763132, 2009.

Tobias, H. J., Kooiman, P. M., Docherty, K. S., and Ziemann, P. J.: Real-Time Chemical Analysis of Organic Aerosols Using a Thermal Desorption Particle Beam Mass Spectrometer, Aerosol Sci. Technol., 33, 170-190, doi:10.1080/027868200410912, 2000.

Turpin, B. J., Saxena, P., and Andrews, E.: Measuring and simulating particulate organics in the atmosphere: problems and prospects, Atmos. Environ., 34, 2983-3013, 2000.

Ulbrich, I. M., Canagaratna, M. R., Zhang, Q., Worsnop, D. R., and Jimenez, J. L.: Interpretation of organic components from Positive Matrix Factorization of aerosol mass spectrometric data, Atmos. Chem. Phys., 9, 2891-2918, doi:10.5194/acp-9-2891-2009, 2009.

Vasiliou, J. G., Sorensen, D., and McMurry, P. H.: Sampling at controlled relative humidity with a cascade impactor, Atmos. Environ., 33, 1049-1056, doi:10.1016/S1352-2310(98)00323-9, 1999.

Veres, P., Roberts, J. M., Warneke, C., Welsh-Bon, D., Zahniser, M., Herndon, S., Fall, R., and de Gouw, J.: Development of negative-ion proton-transfer chemical-ionization mass spectrometry (NI-PT-CIMS) for the measurement of gas-phase organic acids in the atmosphere, Int. J. Mass Spectrom., 274, 48-55, doi:10.1016/j.ijms.2008.04.032, 2008.

Vogel, A. L., Äijälä, M., Brüggemann, M., Ehn, M., Junninen, H., Petäjä, T., Worsnop, D. R., Kulmala, M., Williams, J., and Hoffmann, T.: Online atmospheric pressure chemical ionization ion trap mass spectrometry (APCI-IT-MSn) for measuring organic acids in concentrated bulk aerosol - a laboratory and field study, Atmos. Meas. Tech., 6, 431-443, doi:10.5194/amt-6-431-2013, 2013.

Voisin, D., Smith, J. N., Sakurai, H., McMurry, P. H., and Eisele, F. L.: Thermal Desorption Chemical Ionization Mass Spectrometer for Ultrafine Particle Chemical Composition, Aerosol Sci. Technol., 37, 471-475, doi:10.1080/02786820300959, 2003.
Volkamer, R., Jimenez, J. L., San Martini, F., Dzepina, K., Zhang, Q., Salcedo, D., Molina, L. T., Worsnop, D. R., and Molina, M. J.: Secondary organic aerosol formation from anthropogenic air pollution: Rapid and higher than expected, Geophys. Res. Lett., 33, L17811, doi:10.1029/2006GL026899, 2006.

Weber, R. J., Orsini, D., Daun, Y., Lee, Y. N., Klotz, P. J., and Brechtel, F.: A Particle-into-Liquid Collector for Rapid Measurement of Aerosol Bulk Chemical Composition, Aerosol Sci. Technol., 35, 718-727, doi:10.1080/02786820152546761, 2001.

Williams, B. J., Goldstein, A. H., Kreisberg, N. M., and Hering, S. V.: An In-Situ Instrument for Speciated Organic Composition of Atmospheric Aerosols: Thermal Desorption Aerosol GC/MS-FID (TAG), Aerosol Sci. Technol., 40, 627638, doi:10.1080/02786820600754631, 2006.

Yatavelli, R. L. N. and Thornton, J. A.: Particulate Organic Matter Detection Using a Micro-Orifice Volatilization Impactor Coupled to a Chemical Ionization Mass Spectrometer (MOVI-CIMS), Aerosol Sci. Technol., 44, 61-74, doi:10.1080/02786820903380233, 2010.

Yatavelli, R. L. N., Lopez-Hilfiker, F., Wargo, J. D., Kimmel, J. R., Cubison, M. J., Bertram, T. H., Jimenez, J. L., Gonin, M., Worsnop, D. R., and Thornton, J. A.: A Chemical Ionization High-Resolution Time-of-Flight Mass Spectrometer Coupled to a Micro Orifice Volatilization Impactor (MOVI-HRToF-CIMS) for Analysis of Gas and ParticlePhase Organic Species, Aerosol Sci. Technol., 46, 1313-1327, doi:10.1080/02786826.2012.712236, 2012.

Zelenyuk, A. and Imre, D.: Single Particle Laser Ablation Time-ofFlight Mass Spectrometer: An Introduction to SPLAT, Aerosol Sci. Technol., 39, 554-568, doi:10.1080/027868291009242, 2005 . 